DIW BERLIN

Discussion

Papers
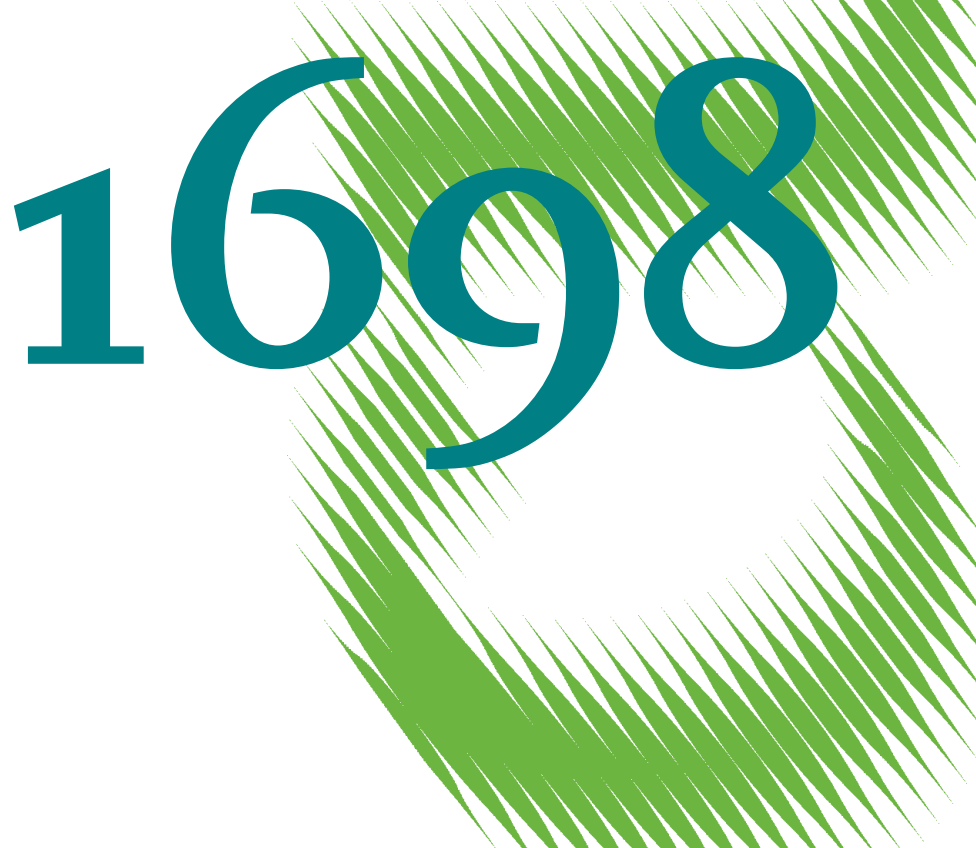

The Rising Longevity Gap by Lifetime Earnings - Distributional Implications for the Pension System 
Opinions expressed in this paper are those of the author(s) and do not necessarily reflect views of the institute.

IMPRESSUM

(C) DIW Berlin, 2017

DIW Berlin

German Institute for Economic Research

Mohrenstr. 58

10117 Berlin

Tel. +49 (30) $89789-0$

Fax +49 (30) $89789-200$

http://www.diw.de

ISSN electronic edition 1619-4535

Papers can be downloaded free of charge from the DIW Berlin website:

http://www.diw.de/discussionpapers

Discussion Papers of DIW Berlin are indexed in RePEc and SSRN:

http://ideas.repec.org/s/diw/diwwpp.html

http://www.ssrn.com/link/DIW-Berlin-German-Inst-Econ-Res.html 


\title{
The rising longevity gap by lifetime earnings - distributional implications for the pension system*
}

\author{
Peter Haan† Daniel Kemptner ${ }^{\ddagger}$ and Holger Lüthen ${ }^{\S}$
}

October 18, 2017

\begin{abstract}
This study uses German social security records to provide novel evidence about the heterogeneity in life expectancy by lifetime earnings and, additionally, documents the distributional implications of this earnings-related heterogeneity. We find a strong association between lifetime earnings and life expectancy at age 65 and show that the longevity gap is increasing across cohorts. For West German men born 1926-28, the longevity gap between top and bottom decile amounts to about 4 years (about 30\%). This gap increases to 7 years (almost 50\%) for cohorts 1947-49. We extend our analysis to the household context and show that lifetime earnings are also related to the life expectancy of the spouse. The heterogeneity in life expectancy has sizable and relevant distributional consequences for the pension system: when accounting for heterogeneous life expectancy, we find that the German pension system is regressive despite a strong contributory link. We show that the internal rate of return of the pension system increases with lifetime earnings. Finally, we document an increase of the regressive structure across cohorts, which is consistent with the increasing longevity gap.
\end{abstract}

Keywords: mortality, lifetime inequality, pensions, redistribution

JEL classification: H55, I14, J11

\footnotetext{
*Acknowledgments: We thank Timm Bönke, Hans Fehr, Ronny Freier, Johannes Geyer, Carsten Schröder and the participants at the 2017 annual congresses of NETSPAR, ECINEQ, IIPF, and VfS for valuable comments. Further, we are grateful to the team at the Research Data Center at the German Federal Pension Insurance and the Thyssen foundation (Project: 10141098) and the DFG (Project HA5526/4-2) for financial support.

${ }^{\dagger}$ DIW Berlin, FU Berlin \& NETSPAR, phaan@diw.de

${ }^{\ddagger}$ DIW Berlin, dkemptner@diw.de

${ }^{\S}$ FU Berlin \& DIW Berlin, hluethen@diw.de
} 


\section{Introduction}

Inequality of lifetime earnings, consumption, and wealth has been increasing over time and between cohorts in most OCED countries, see e.g. Kopczuk et al. (2010), Attanasio and Pistaferri (2016), or Saez and Zucman (2016). One other important dimension of inequality which is highly correlated with the economic inequality is the heterogeneity in life expectancy Cutler et al. (2006).

This paper provides novel evidence about the heterogeneity in life expectancy and how this heterogeneity has evolved between cohorts. Further we analyze the distributional implications of heterogeneity in life expectancy for the pension system. First, we document the heterogeneity in life expectancy by lifetime earnings and show how the earnings-related longevity gap has evolved over 24 cohorts, born 1926 through 1949. Second, in addition to this direct relation between lifetime earnings and life expectancy we focus on an important indirect relation: we extend the analysis of life expectancy to the household context and analyze how the life expectancy of widows depends on their husband's lifetime earnings. Further, earnings-related heterogeneity does not only mean that individuals with higher lifetime earnings enjoy a longer life, it also has consequences for the inequality of lifetime income through the pension system: individuals with higher lifetime earnings enjoy a longer life and therefore they receive pensions for a longer period. The final section of this paper focuses on this link and quantifies the distributional implications for the German pension system, which has, in contrast to Social Security, a strong contributory link.

The first part of the empirical analysis is based on administrative data covering the universe of German retirees and focuses on West German men. The data includes information about pension entitlements, which directly depend on lifetime earnings, year of birth, and date of death. This enables us to estimate age-specific mortality rates conditional on birth cohort and decile of lifetime earnings. Based on these mortality rates, we derive cohort- and earnings-specific life expectancies at age 65 and provide evidence of how earnings-specific life expectancies changed over cohorts. In a similar manner, we show how the husband's lifetime earnings relate to the heterogeneity of widows' life expectancies and how this heterogeneity differs between cohorts.

In the second part, we focus on the distributional implications of heterogeneous life expectancy for the pension system. We link the estimated mortality rates to administrative biography data for cohorts 1935-1949. We then calculate cohort-specific distributions of individual pension wealth and of internal rate of returns (IRR). To quantify the distributional implications, we compare distributions of pension wealth and IRR 
with heterogeneous mortality rates to distributions for which we impose homogeneous mortality rates. Finally, we extend the analysis to the household context and account for survivor benefits for spouses and, using additional assumptions, we provide evidence on how mortality prior to age 65 may affect the distributional implications.

We find a strong association between lifetime earnings and life expectancy at age 65 and show that the longevity gap is increasing across cohorts. For West German men born 1926-28, the difference in life expectancy at age 65 between top and bottom decile amounts to about 4 years or close to $30 \%$. For this group, the gap increases to about 7 years (almost 50\%) for cohorts 1947-49. Further, we show that the increase in the longevity gap is driven by a larger increase in life expectancies in the upper deciles. For individuals in the bottom decile, life expectancy hardly changed over time. The analysis on the household level documents important indirect effects which reinforce the role of lifetime earnings for life expectancy. We show that life expectancy of widows is increasing with the lifetime earnings of the partner. For widows married to men born in 1926-28 we find a longevity gap between top and bottom quintile of male lifetime earnings of about 2.5 (more than 10\%) year which increases to 4 years for widows married to men boron in 1947-49 (about 20\%).

The earnings-related heterogeneity in life expectancy has sizable and relevant distributional consequences for the pension system. We find that the German pension system is progressive when we impose homogeneous life expectancy within a cohort. However, when accounting for heterogeneous life expectancy, the distributional implications turn around: we show that the IRR of pension contributions increase in lifetime earnings, making the pension system regressive. Further, we document - consistently with the increasing longevity gap - an increase of the regressive structure across cohorts.

Our study is related to the literature that focuses on heterogeneity in life expectancy and related distributional implications. Prior studies document heterogeneity in life expectancy and an increasing longevity gap by earnings over cohorts or time using survey data, such as the Health and Retirement Survey (HRS), administrative social security records, or tax records; see e.g. Kitagawa and Hauser (1973), Waldron (2007) and Chetty et al. (2016). von Gaudecker and Scholz (2007) and Kiebele et al. (2013) focus on Germany. Based on administrative pension data they show that longevity is strongly associated with lifetime earnings and socio-economic status and they provide evidence for an increasing longevity gap for individuals with low and high socio-economic status between two time periods, 1995-1996 and 2007-2008. In our analysis we extend this literature; we study the inequality of life expectancy not only on the individual level but we provide as well evidence about the indirect effect in the household context. More- 
over, we provide novel evidence for Germany as we document the changes in longevity differences by decile of lifetime earnings over a long time period, namely for cohorts 1926 - 1949.

In addition, our study contributes to the literature on the distributional implications of heterogeneous life expectancy for transfer programs and the pension system, e.g. Gustman and Steinmeier (2001), Coronado and Glass (2002), Liebman (2002), and more recently, Auerbach et al. (2017) for simulation studies for the US, or Breyer and Hupfeld (2009) for Germany 11 Further, several studies theoretically analyze the optimal design of the pension system when life expectancy is heterogeneous (for an overview see Pestieau and Ponthiere (2016) ) or use structural models to quantify the distributional and welfare implications of pension reforms, e.g. Fehr et al. (2013), Bagchi (2016), and Sanchez-Romero and Fürnkranz-Prskawetz (2017). For example Sanchez-Romero and Fürnkranz-Prskawetz (2017) develop an overlapping generations model with heterogeneous life expectancy, calibrated to the US economy. They confirm the findings of the simulation studies for the US: because of the earnings-related longevity gap Social Security does not redistribute from high skilled individuals to low skilled individuals despite its progressive design. Our analysis differs from the studies for the US in two important dimensions. First, we focus on the distributional implications for the German pension system which has a strong contributory link. Second, instead of using a simulation model to project the implications of hypothetical pension reforms, we use high quality administrative data to document the distributional implications of the cohort-specific pension system in combination with the evolution of cohort-specific heterogeneity in life expectancy.

The paper is organized as follows. Section 2 provides information on the institutional background and describes the data. In the third part we provide descriptive evidence on mortality rates and discusses the empirical model and the estimation results of cohortspecific heterogeneity in life expectancies and their evolution for men and their surviving spouses. In Section 4, we link these findings to the pension system and analyze their distributional implications. Section 5 concludes.

${ }^{1}$ Breyer and Hupfeld 2009) estimate the relationship between annual earnings and life expectancy of German retirees and derive a hypothetical pension system that guarantees distributive neutrality. 


\section{Institutional background and data}

\subsection{Institutional background}

The German statutory pension system is designed as a defined benefit, pay-as-you-go system. Most employees are mandatorily insured ${ }^{2}$ and contribute a percentage of their yearly gross earnings. For their contributions, individuals acquire pension entitlements in form of earnings points. The number of points are based on the ratio of the individual wage to the average wage. An individual earns exactly one point (per year) if their yearly wage corresponds to the average yearly wage, and more (less) points if their wage exceeds (is below) the average wage. There is a cap for pension contributions, which corresponds to about two times the average wage, implying that individuals can only earn up to two earnings points per year 3 Employees accumulate earnings points over their full working life. At retirement, the total sum of points is multiplied with the pension value to determine the monthly gross pension. 4

In contrast to Social Security in the US, the German pension system has a strong contributory link: annual pensions are in principle proportional to contributions during the working life. However, the pension system includes early retirement schemes that have progressive distributional implications. In particular, for the cohorts considered, the pension system offers pathways to early retirement before the normal retirement age of 65 to disabled or unemployed individuals and to those with a long working career $5^{5}$ Individuals can also claim an invalidity pension before being eligible for an old-age pension. Starting with individuals born after 1937, the specific design for the different pathways changed as pension reforms introduced deductions for early retirement. These deductions amount to $3.6 \%$ per year of early retirement 6 Still, early retirement remains financially attractive because the actuarial adjustments are too small to be "fair" (Börsch-Supan and Schnabel, 1998).

\footnotetext{
${ }^{2}$ Some specific occupations are exempted as they have their own pension funds, e.g. lawyers and physicians.

${ }^{3}$ The social security threshold in West Germany in 2017 was EURO 76,200 per year, corresponding to a maximum of 2.05 earnings points.

${ }^{4}$ This value is adjusted every calendar year and was EURO 30.99 in 2017.

${ }^{5}$ For women there exists an additional early retirement scheme.

${ }^{6}$ The deductions are gradually introduced and fully apply for cohorts born after 1945 . Since the pathways differ in normal and early retirement age, maximal deductions vary between $7.2 \%$ and $18 \%$. For a detailed description of the rules and descriptive evidence about the pension contributions and pension entitlements of early retirees, see Lüthen (2016).
} 


\subsection{Pension data}

For individuals covered by the pension system, the pension insurance collects the information necessary to calculate all potential pensions at any point in time; in particular the data includes information about entitlements, contributions, date of death and demographic variables like gender or cohort. The data is stored in thematic datasets of which we use two for our analysis. Our study focuses on West German men and their widows 7

In the first part of the analysis, to estimate heterogeneous mortality, we employ the SK90, which covers the universe of all pensioners 8 This data is available for calendar years 1992-2015 and contains information about individual pension entitlements, pension level, survivor pensions, and time of death 9 We focus on life expectancy at age 65 when all individuals are retired. This avoids selection problems through varying retirement ages in the different pathways, e.g. early retirement of disabled individuals. We concentrate on cohorts 1926-1949, as they can be observed at age 65 and at later ages ${ }^{10}$ More specifically, we observe individuals born in 1926 between ages 65 and 88 . In contrast, individuals born in 1949 can only be observed at age 65. For the estimation of age-specific mortality rates, we also include individuals from earlier cohorts 1905-1925. While we do not study life expectancies for these cohorts, we exploit the information for the identification of age profiles of mortality rates at higher ages. In total, we use information on 63 million surviving and 3.4 million decedent men. Table A.1 in Appendix I displays the numbers by cohort.

For institutional reasons, the data does not allow to analyze the relationship between women's lifetime earnings and their life expectancies 11 Instead we us the information about female mortality rates to explore a potentially important indirect relation between life time income and life expectancy: we analyze the link between widows' life expectancy

\footnotetext{
${ }^{7}$ We exclude East Germans as the information on employment biographies of the cohorts considered here cannot be directly linked to their lifetime earnings; a large fraction of this information is related to the earnings history and the pension system of the GDR.

${ }^{8}$ The SK90 can be accessed via controlled remote computing only. There is no publicly available description. However, there is a similar publicly available $1 \%$ sample, the SUFDemografie, which can be obtained from the Research Data Center of the German Pension Insurance.

${ }^{9}$ More specifically, we observe if an individual pension was discontinued during the 12 months preceding the reporting date (November 30th). For an old-age pension, the only reason for a discontinuation is the death of the respective individual.

${ }^{10}$ Since these cohorts are retired at age 65 at the latest, age 65 is the earliest possible age to observe an entire distribution of pension entitlements.

${ }^{11}$ Until 1967, it was legally allowed for women to leave the pension system at the time of their marriage and gain the monetary value of their collected pension entitlements. Until 1995, however, these women could reenter the pension system through retroactive payments, which were financially attractive. In the SK90 data we cannot observe if a woman returned to the pension system or not.
} 
and their husbands' lifetime earnings. For this analysis, we employ the information on survivor pensions for widows in the data. We use information about 27.5 million survivors and 2 million decedents (see Table A.2 in Appendix I). Again, also for widows, earlier cohorts born before 1926 serve to identify the age-profile of mortality.

The second part of the analysis focuses on the distributional effects of heterogeneous life expectancy on the pension system. For the calculation of pension benefits, we need exact information about the individual employment and contribution histories which is not available in the data that covers the universe of the pensioners. Therefore, we use the Versicherungskontenstichprobe (VSKT) ${ }^{12}$ which is a random sub-sample of all individuals covered by the pension insurance. The VSKT includes complete monthly employment biographies from ages 14 to 67 for cohorts 1935 through 1985. We concentrate on individuals born between 1935 and 194913 This leaves us with 14,335 West German men (see table A.3 in Appendix I for the number of observations by decile and cohort group).

German pension data cover about $80 \%$ of West German men (Bönke et al., 2015). The data does not cover periods of civil service or self-employment. This implies that selfemployed individuals or civil servants are included with only a fraction of their employment biography and low amounts of pension entitlements. Therefore, the composition of individuals at the lower end of the entitlement distribution is very heterogeneous: On the one hand, it includes long-term unemployed with very low lifetime earnings and, on the other, self-employed and civil servants with potentially high lifetime earnings. Thus, a clear interpretation of mortality rates for those with low entitlements is not possible (see Table A.4 in Appendix I for a depiction of the average time spent in different labor market states by lifetime earnings decile). We follow previous studies, e.g. Kiebele et al. (2013) and von Gaudecker and Scholz (2007), and restrict the sample. In our analysis, we focus on individuals with at least 30 accumulated earnings points. This corresponds to about $75 \%$ of all pensioners ${ }^{14}$

\footnotetext{
${ }^{12}$ This data is called FDZ-RVVSKT2002, $2004-15$ Bönke and is accessible through controlled remote computing only. A $25 \%$ subsample is available as scientific use file.

${ }^{13}$ We exclude those with special pension arrangements, especially miners. Miners' pension contributions include certain special arrangements like expanded healthcare. Thus, miners' contributions are not directly comparable to the contributions of regular retirees. Still, our results are robust to an inclusion of miners.

${ }^{14}$ Mortality results are robust when changing the threshold to 25 earnings points. Further, we also show estimated life expectancies that are based on the unrestricted sample in Appendix VI
} 


\subsection{Lifetime earnings}

As discussed in e.g. Auerbach et al. (2017), it is important to use a long term measure of earnings, such as lifetime earnings, to understand the link between earnings and life expectancy: the variation in short run measures, such as annual earnings, might be partly driven by transitory earnings shocks or short term health shocks. As mentioned above the social security data includes information about the the earnings of the full working life, this allows us to construct individual lifetime earnings for our analysis.

In the data annual information about earnings is right-censored at the contribution ceiling. Bönke et al. (2015) show that this concerns about $7 \%$ of all earnings of West German employees per year. At the same time, they provide evidence that earnings ranks and levels are highly persistent over time. This implies that lifetime earnings estimations based on pension data are censored as well; however, the censoring is limited to individuals at the top of the earnings distribution. In the following analysis, we consider deciles of lifetime earnings, thus we use ranks instead of levels of lifetime earnings. In this way, our estimates are not affected by the censoring. Figure A.1 in Appendix I provides the decile cut-off values at age 65 by cohort. The cut-off values are expressed in earnings points and applied to all later ages after age 65 . This avoids selection problems caused by differential mortality.

\section{Heterogeneity in life expectancies across cohorts}

This section analyzes the heterogeneity in life expectancy across cohorts. First, we present descriptive evidence about the heterogeneity of age-specific mortality risks. Then we derive a model to estimate individual life life expectancy at age 65 and show how this differs between cohorts and earnings deciles. Finally, we look at the household context and analyze how the life expectancy of widows varies across cohorts and spousal lifetime earnings.

\subsection{Descriptive Evidence}

Figure 1 presents observed age-specific survival rates after age 65 a) by lifetime earnings decile and b) by birth cohort. We depict the corresponding mortality rates for cohorts 1926-1949 in Figure A.2 in Appendix I. Due to our sample structure, mortality and survival rates at higher ages are only observed for older cohorts. Panel (a) supports the well known finding of a positive link between level of lifetime earnings and age-specific survival probabilities, see e.g Cutler et al. (2006). In particular, the data show that sur- 
Figure 1: Survival of West German men by lifetime earnings and birth cohort at age 65

(a) By decile

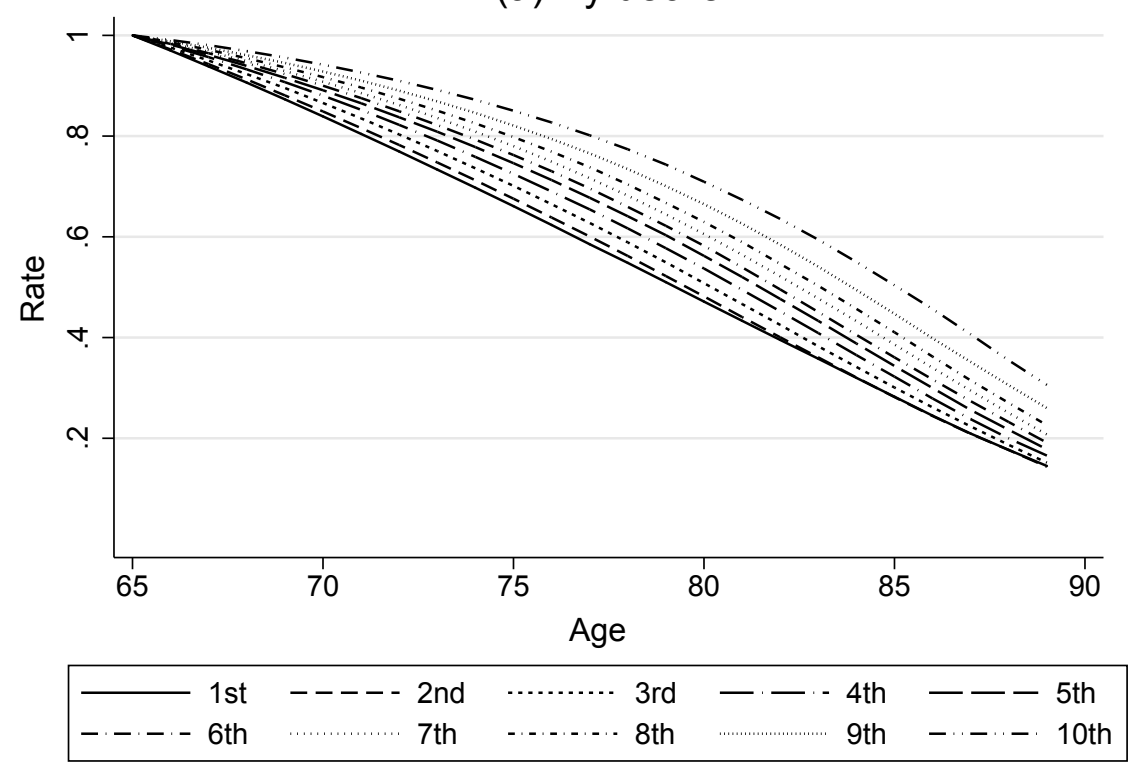

(b) By cohort group

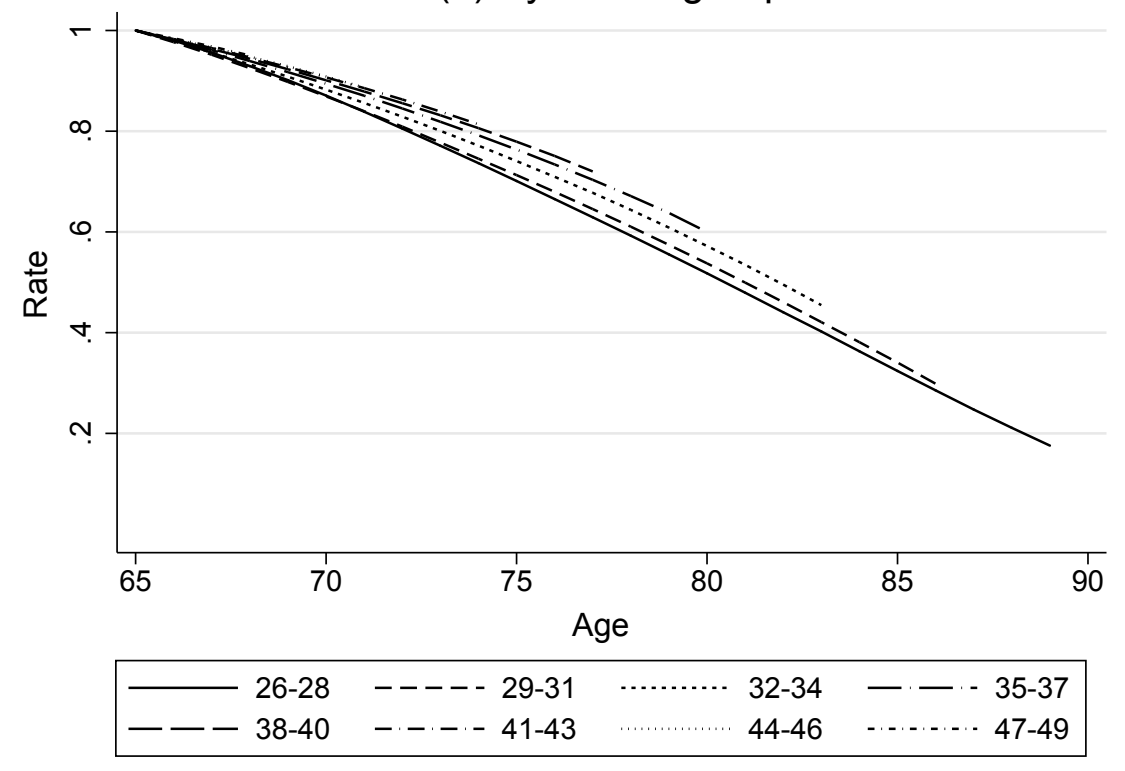

Source: SK90, waves 1992-2015, own calculations. Notes: The survival rates are computed using the observed mortality rates for cohorts 1926-1949 (as depicted in Figure A.2 in Appendix I). Panel (a): survival rates at age 65 by decile of lifetime earnings. Panel (b): survival rates at age 65 by birth cohort group. 
vival probabilities are highest for individuals in the top decile and decline monotonically across deciles. At age 70, survival probabilities for the top decile are above $90 \%$ and roughly 10 percentage points higher than for the lowest decile. This gap increases to about 20 percentage points at age 80 and later. Panel (b) displays age-specific survival rates after age 65 by cohort. In line with e.g. Oeppen and Vaupel (2002), we find a distinct increase in age-specific survival rates for younger cohorts. For instance, cohorts 1926-28 have a survival probability of about $70 \%$ at age 75 , which increases to about $80 \%$ for cohorts 1941-43.

\subsection{Model for life expectancy}

Since we do not observe mortality rates over the entire relevant age range, we estimate conditional age-specific mortality rates by earnings decile between ages 65 to 99 . This allows us to derive cohort and earnings-specific life expectancies. We employ a logistic regression to estimate the probability of death within the next 12 months conditional on age. The age effects are heterogeneous and may vary by earnings decile. Further, we account for cohort-specific fixed effects, fixed effects of earnings deciles and interactions of cohort and earnings fixed effects. The log-odds have the following form:

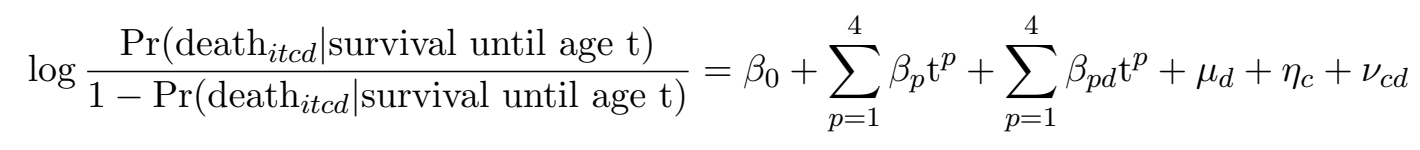

where individual $i$ is in lifetime earnings decile $d$ of cohort group $c$ and of age $t$. Cohorts are grouped into fifteen 3-year birth cohort groups. Deciles are cohort-specific and computed at age $65 \sqrt{15}$ We allow for a flexible specification of age effects (4th order polynomial), which is strongly supported by the comparison to a model with non-parametric age effects (see Figure A.6 in Appendix VI). The estimation includes cohorts born 1905 through 1949. Since we cannot observe lifetime earnings at age 65 for individuals born before 1926, we refrain from deriving differential mortality rates for cohorts 1905-1925. As mentioned above, we use information on these individuals to guarantee empirical support for the relationship between age and mortality at high ages 16 Further, the earnings fixed effects vary by cohort and age. For the identification of earnings-specific age effects

\footnotetext{
${ }^{15}$ See Figure A.1 in Appendix I for details. Cut-off points are fixed within cohort-groups and are not age-specific. Otherwise, differential mortality causes a selection problem because the cut-off points and, thus, the composition of individuals in the different deciles would change with age.

${ }^{16}$ For cohorts $1905-1925$, we use cut-off values from cohorts $1926-28$ as a proxy. Since earnings points are a relative measure and depend on the average wage in the respective year, the variation in cut-off values over cohorts is small.
} 
we assume that age effects on log-odds of mortality have the same functional relationship across cohorts. Observed patterns of mortality rates support this assumption: As shown in Figure A.3 in Appendix 1, the relationship between age and mortality follows a similar pattern across cohort groups. Figure A.3 also demonstrates the importance of heterogeneous age effects by decile. We find that differences in log-odds of mortality decrease with age. In more detail, individuals with high mortality risks seem to die more often at younger ages in lower deciles; this leads to a decrease in the heterogeneity of mortality risks across deciles at higher ages ${ }^{17}$

Tables A.5, A.6, and A.7 in Appendix II present our parameter estimates. Due to the large number of interaction terms, specific parameters are difficult to interpret. For a clear presentation we use the parameter estimates to predict conditional age-specific mortality rates and calculate the corresponding life expectancies at age 65 for all cohort groups and earnings deciles.

\subsection{Results for men}

Figure 2 shows the heterogeneity in life expectancy at age 65 by earnings decile for men born between 1926 and 1949. The figure documents two key findings: First, life expectancy at age 65 strongly varies between earnings deciles and, second, the longevity gap by earnings increases across cohorts.

For cohorts 1926-28, life expectancy at age 65 amounts to about 18 years at the top decile and 14 years at the bottom decile. Hence, we find a longevity gap between the lifetime rich and the lifetime poor of roughly 4 years or in relative terms of nearly $30 \%$. This longevity gap increases over cohorts: 5 years for cohorts 1932-34, 6 years for cohorts 1938-40, and, finally, 7 years for cohorts 1947-49 which is equivalent of a relative difference of almost 50\% 18 Larger increases in life expectancies in the upper deciles drive this growth. For the cohorts considered, upper deciles experience an increase of about 4 years in life expectancy at age 65 , whereas lower deciles gain only about 1 year. Both life expectancy and longevity gap increase monotonically with earnings decile. Although, quantitatively, the picture is quite different for cohorts 1947-49 than for cohorts 1926-28, the ordering remains and becomes even more pronounced.

\footnotetext{
${ }^{17}$ Neglecting heterogeneous age effects leads to an overestimation of the longevity gap for younger cohorts as they are only observed at younger ages.

${ }^{18}$ Changes in the heterogeneity of life expectancy can be due to both changes in the lifetime earnings distribution and changes in the effects of earnings inequality. Furthermore, Currie and Schwandt (2016) show that cohort-specific changes in life expectancy at age 65 can be affected by composition effects (e.g. changes in infant mortality).
} 
Figure 2: Life expectancies of West German men at age 65

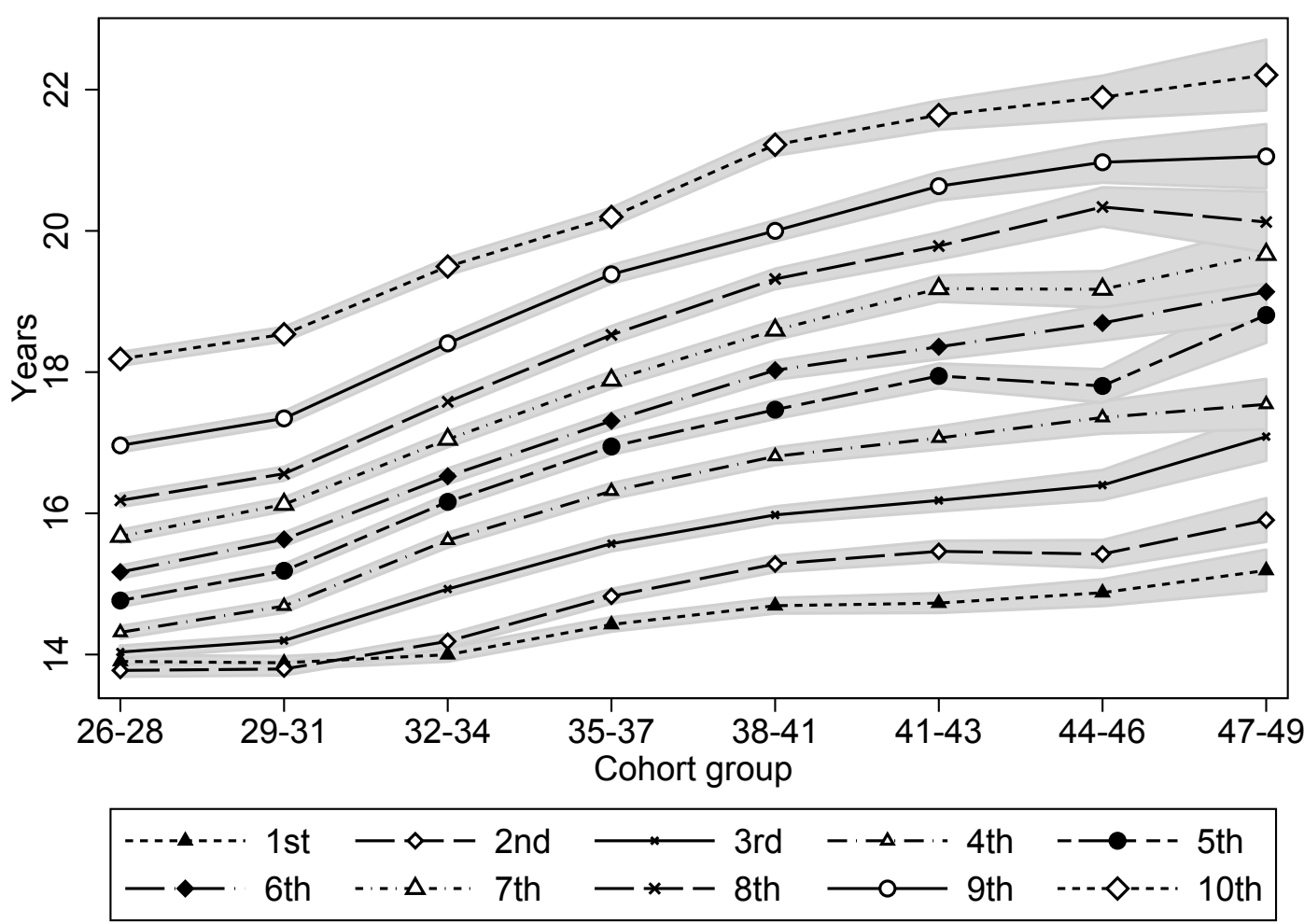

Source: SK90, waves 1992-2015, own calculations. Notes: Life expectancy in years after age 65. Predictions are based on estimated model parameters. Grey areas indicate 95\% confidence bands estimated with the Delta method. The calculation assumes that individuals die with probability 1 at age 100 .

\subsection{Results for surviving spouses}

So far the literature has only concentrated on the relationship between earnings inequality and individual life expectancy, however implications for the household context are also important. This is particularly true for female spouses, who, for the cohorts considered, often have lower lifetime earnings and pension entitlements than their husbands and rely on their husband's entitlements. Upon becoming widowed, they receive survivor pensions, which depend on earnings history and pension entitlements of the deceased spouse.

To study the relation between individual earnings and the life expectancy of widows as well as its evolution across cohorts, we modify the afore mentioned framework. Instead 
of male's mortality, we model the widow's mortality conditional on the deceased male's birth cohort, his lifetime earnings, and a flexible function of his age. Due to the smaller sample size - in particular for younger ages - we pool two of the cohort groups and consider quintiles instead of deciles of earnings 19

We estimate the widows' mortality rates for deceased males' hypothetical ages up to 109 (instead of 99) ${ }^{20}$ Hence, we account for a longer period of potential survival when computing widows' life expectancies. This is necessary for an accurate prediction of the widows' remaining life expectancy conditional on the husband's death at age 65 because women have a higher life expectancy and the surviving widows are on average 3 years younger than their deceased husbands. Since the average age difference between the spouses is very similar across earnings quintiles and cohorts, the widows are on average about 62 years in all considered groups.

Figure 3 presents the results of remaining life expectancy of widows of a spouse that passed away at age 6521 Overall, our results provide a clear picture: not only the individual life expectancy is related to lifetime earnings but also the life expectancy of the spouse. West German women with a partner in the top earnings quintile have a significantly higher life expectancy than women with a partner in the bottom quintile. Further, the difference in life expectancy is increasing across cohorts - the longevity gap between the top and the bottom quintile is about 2.5 years (more than 10\%) for cohorts 1926-1931 and increases to 4 years (about 20\%) for cohorts 1944-1949. Thus, the results on the household level reinforce the previous findings about the link between lifetime earnings and individual life expectancy and the increasing longevity gap.

\section{The distributional implication of the longevity gap for the pension system}

In the following, we concentrate on the distributional consequences of the documented heterogeneity and the increasing longevity gap for the pension system. Heterogeneity in life expectancy can offset progressive effects or can lead to regressive effects in a

\footnotetext{
$\overline{{ }^{19} \text { Widow i's mortality risk is modeled }}$ as $\log \frac{\operatorname{Pr}\left(\text { death }_{i t c q} \mid \text { survival until age } \mathrm{t}\right)}{1-\operatorname{Pr}\left(\text { death }_{\text {itc }} \mid \text { survival until age } \mathrm{t}\right)}=\beta_{0}+\sum_{p=1}^{4} \beta_{p} \mathrm{t}^{p}+$ $\sum_{p=1}^{4} \beta_{p q} \mathrm{t}^{p}+\mu_{q}+\eta_{c}+\nu_{c q}$, where $\mathrm{q}$ is the quintile of the deceased husband's lifetime earnings, $\mathrm{c}$ his birth cohort group, and age $\mathrm{t}$ the age that the deceased husband would have reached at the respective reporting date. As widows only enter the sample after the spouse's death, we do not use quintile cut-offs from survivor pensions. This would cause a selection problem at age 65 as women from bottom quintiles would appear disproportionally. Instead, we use our cut-offs for men at age 65 to define the quintiles.

${ }^{20}$ In order to cover the longer age range, we consider birth cohorts from 1890 (instead of 1905) to 1949.

${ }^{21}$ Parameter estimates of the modified model for widows can be received from the authors upon request.
} 
Figure 3: Life expectancies of widows after the husband's death at age 65

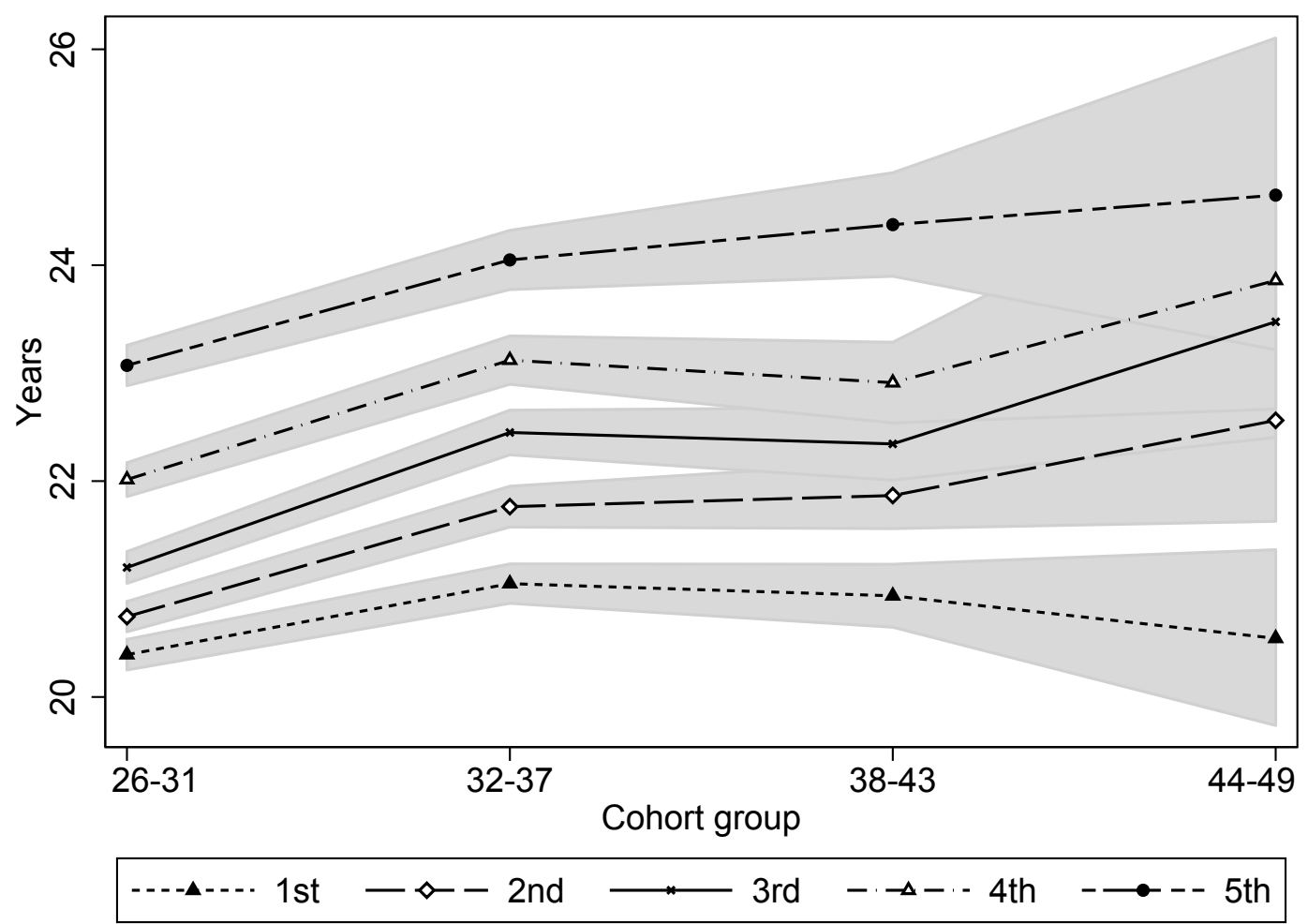

Source: SK90, waves 1992-2015, own calculations. Notes: Life expectancy of widows in years, conditional on her husband's death at age 65. Predictions are based on estimated model parameters. Grey areas indicate $95 \%$ confidence bands estimated with the Delta method. The calculation assumes that widows die with probability 1 at the age when the spouse would have turned 110 .

proportional pension system. A proportional pension system is ex ante distributionally neutral if all individuals have the same life expectancy and enter retirement at the same age. However, if ex ante life expectancy differs systematically between groups, e.g. if life expectancy is positively correlated with lifetime earnings, high earners receive their pensions for a longer duration and, thus, their pension wealth is relatively higher.

To isolate the distributional implications of heterogeneous life expectancy for the pension system, we compare the distributions of pension wealth and internal rates of return (IRR) in two different scenarios. In the first scenario, we use the estimated heterogeneous mortality rates and in the second scenario we impose homogeneous mortality rates defined as cohort-specific averages. Pension wealth is calculated as 2015 real present value 
of expected pensions at age $65{ }_{22}^{22}$ Pension wealth comparisons allow us to look at gains and losses of total pension benefits related to heterogeneous life expectancy across the distribution. To understand the link between pension contributions and benefits, we analyze the distribution of IRR, which is a measure of the pension system's rentability. The IRR treats individual pension contributions as a financial investment: The IRR is the average individual interest rate that needs to be paid on pension contributions to yield the expected stream of pensions. The cohort-specific distribution of IRR provides direct information about the distributional effects of the pension system: higher (lower) IIR in the upper deciles directly suggest a regressive (progressive) distributional effect of the pension system (see e.g. Gustman and Steinmeier (2001)) ${ }^{23}$ Appendix III provides details about the calculation of both pension wealth and IRR.

\subsection{Inequality of Pension Wealth}

Panel (a) of Figure Appendix III displays the distribution of pension wealth calculated with heterogeneous life expectancy by decile for five different cohort groups. By definition, pension wealth increases by decile as the lifetime rich have made more pension contributions. However, consistent with an increasing longevity gap, the pension wealth distribution changes across cohorts. While for cohorts 1935-37, the difference in pension wealth between top and bottom decile amounts to about 320,000 Euro, this difference increases to about 440,000 Euro for cohorts 1947-49.

In Panel (b) of Figure Appendix III we show the difference in pension wealth between the different scenarios with heterogeneous and homogeneous mortality rates. We find that pension wealth is indeed higher for deciles above the median under the assumption of heterogeneous mortality, whereas deciles below the median experience a decline. These distributional implications become more pronounced across cohorts. While the top decile of cohorts 1935-37 gains about 80,000 Euro when accounting for heterogeneous mortality, the lowest deciles lose about 30,000 Euro. For cohorts 1947-49, the gain increases to more than 110,000 Euro for the top decile and the loss to nearly 50,000 Euro for the bottom deciles.

Finally, cohort-specific Gini coefficients of pension wealth (Table 1) confirm these findings. When allowing for heterogeneous mortality, the Gini increases from 0.162 to 0.195 across cohorts; under the assumption of homogeneous mortality both level and

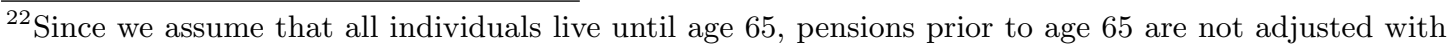
mortality rates.

${ }^{23}$ Such an approach might raise concerns about minimum pensions where small contributions lead to an extremely high return. Due to our sample selection, this does not constitute a problem. All individuals receive a pension above the minimum pension level.
} 
Figure 4: Average pension wealth at age 65: heterogeneous and homogeneous mortality

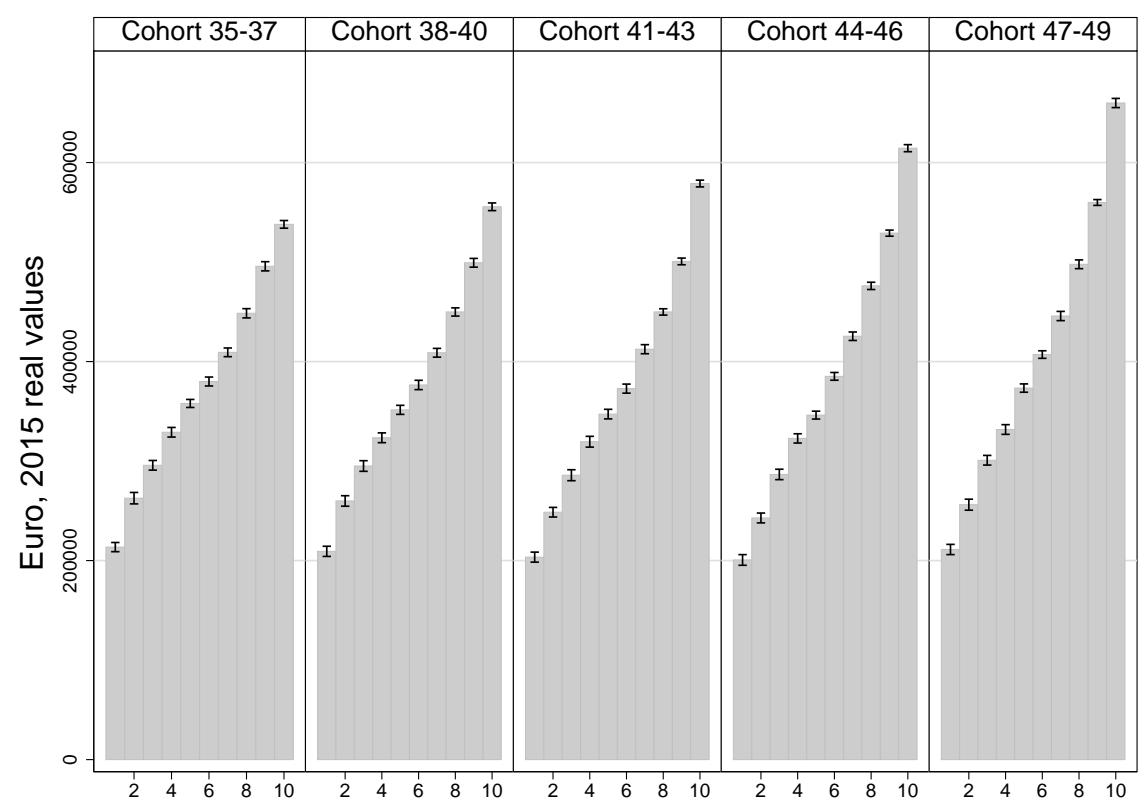

(a)

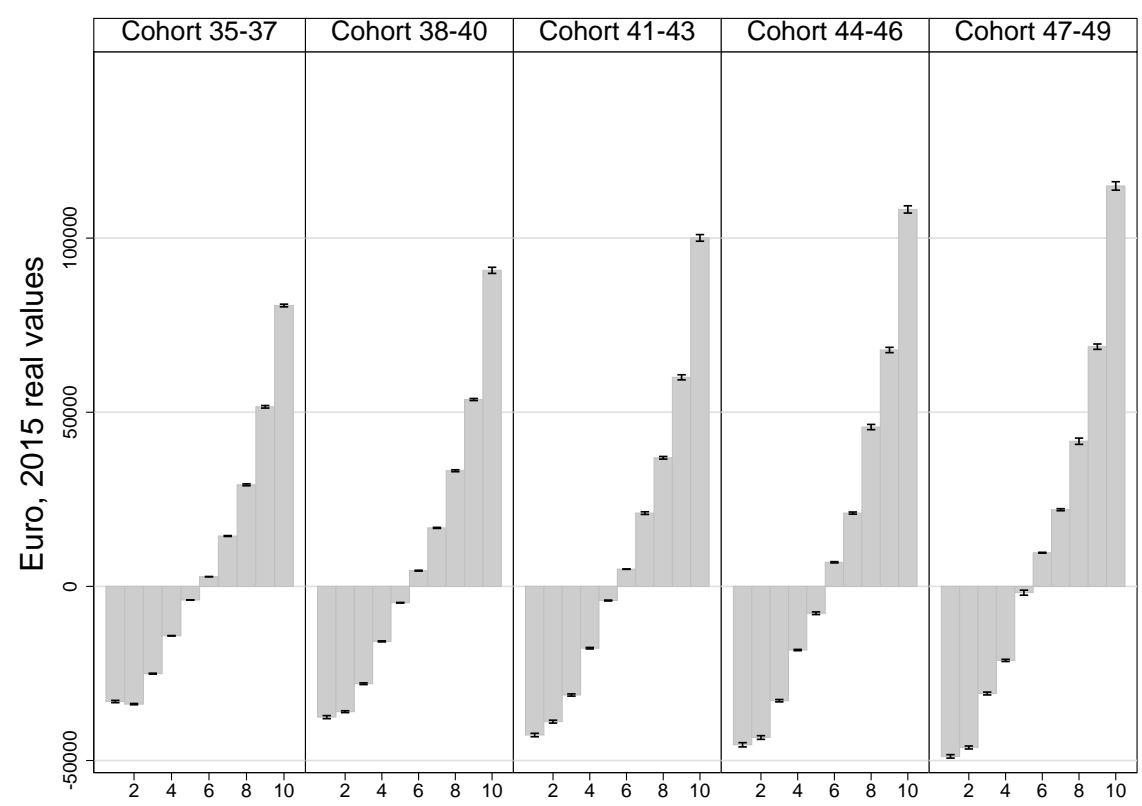

(b)

Source: FDZ-RVVSKT2002, 2004-15_Bönke, own calculations.Notes: Pension wealth at age 65 in real 2015 values by decile and cohort group. 95\% confidence bands account for sample variation. Panel (a): levels of pension wealth with heterogeneous mortality. Panel (b): difference between pension wealth with and without differential mortality. 
Table 1: Ginis of pension wealth at age 65: heterogeneous and homogeneous mortality

\begin{tabular}{lccccc}
\hline \hline Cohort & $35-37$ & $38-40$ & $41-43$ & $44-46$ & $47-49$ \\
\hline & & & & & \\
Heterogeneous mortality & 0.162 & 0.166 & 0.180 & 0.189 & 0.195 \\
Homogeneous mortality & 0.117 & 0.116 & 0.122 & 0.127 & 0.133 \\
\hline Difference & 0.045 & 0.05 & 0.058 & 0.062 & 0.062 \\
\hline \hline
\end{tabular}

Notes: Ginis of pension wealth in 2015 real values by cohort group.

increase of the Gini are lower: from 0.117 to 0.133 . Hence, the difference between the Gini coefficients in the two scenarios increases from 0.45 to 0.62 between cohorts 1935-37 and 1947-49.

\subsection{Internal rate of return}

In Figure 5, we turn to the IRR and provide direct information about the distributional effects for the pension system. Panel (a) presents the IRR under the assumption of homogeneous mortality and Panel (b) under the assumption of heterogeneous mortality. Figure 6 displays the difference between the two scenarios.

When imposing homogeneous mortality, we find the expected progressive pattern of the IRR. This pattern is related to early retirement schemes and disability arrangements in the German pension system, which favor the lifetime poor, see Section 2. For example, for cohorts 1935-37 we find an IRR of $1.7 \%$ in the lowest and of about $1 \%$ in the highest decile ${ }^{24}$ When comparing the distributions of the IRR across cohorts, two findings emerge. First, the overall level of IRR decreases across cohorts, which describes the declining rentability of the pension system. Second, although the IRR distribution changes across cohorts, the relative distance between upper and lower deciles remains fairly similar.

The distributional implications for the pension system completely reverse when we account for heterogeneous life expectancy by lifetime earnings. Panel (b) of Figure 5 shows the distribution of IRR with heterogeneous mortality rates: IRR increases with lifetime earnings, implying a regressive pension system. This holds across all cohorts, although the structure of the IRR differs. For the cohorts 1935-37, we find a u-shaped

\footnotetext{
${ }^{24}$ Our estimates of the IRR are slightly lower than in Lüthen $(2016)$, since we exclude individuals with very short employment biographies and long pension benefit periods. Other studies (e.g. Schröder (2011)) as well as official statements from the pension insurance report nominal IRR between $2 \%$ and $3 \%$. Given an average inflation rate of about $2.4 \%$ since 1950 , these estimates are in line with our results.
} 
Figure 5: Returns of West German men without and with heterogeneous mortality

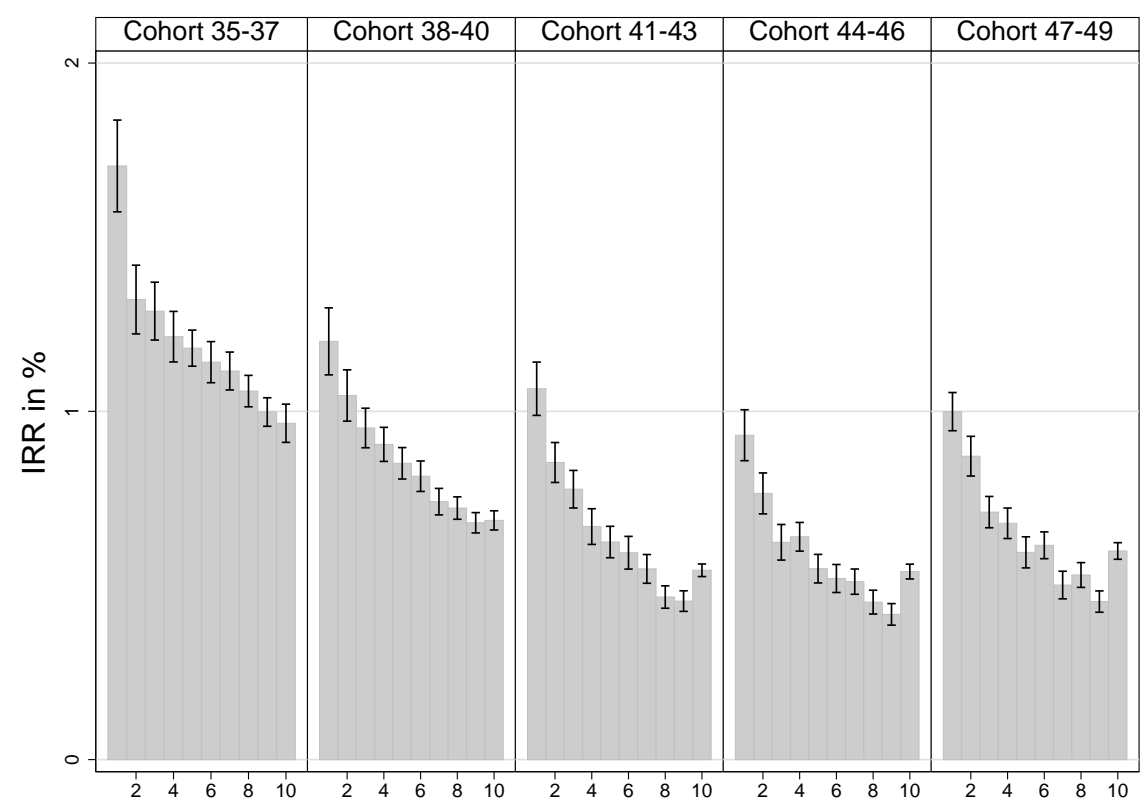

(a)

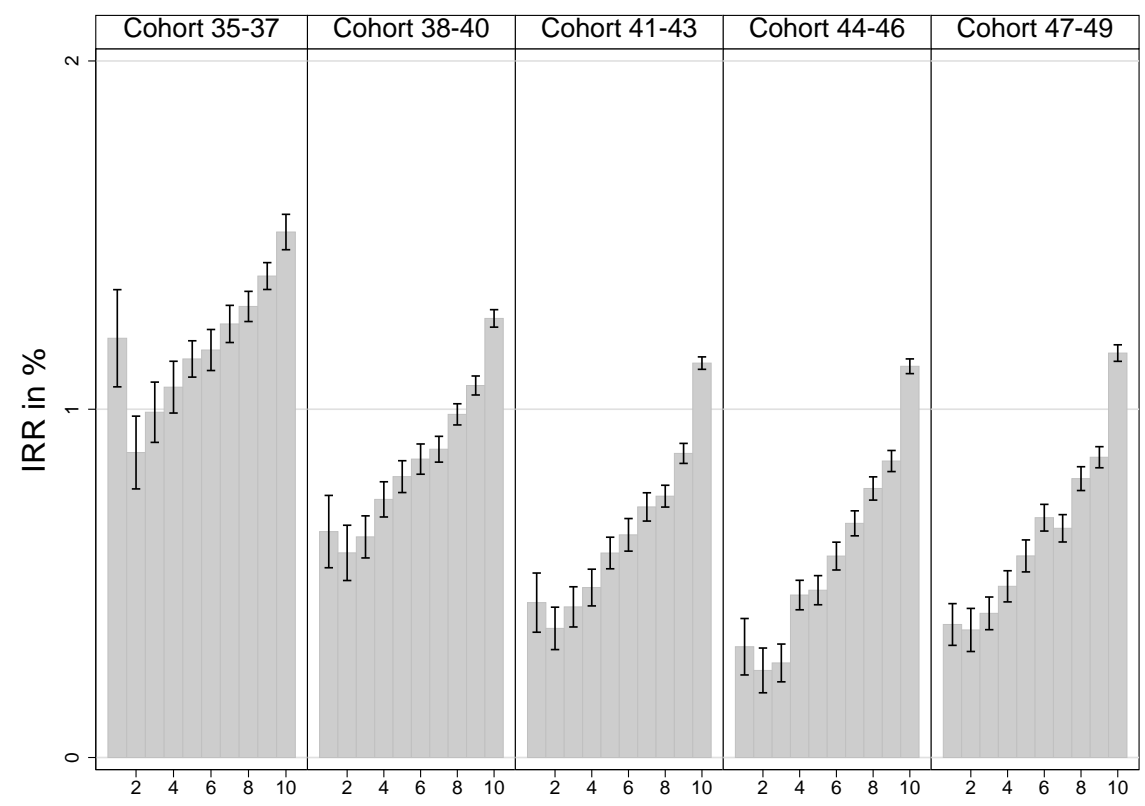

(b)

Source: FDZ-RVVSKT2002, 2004-15_Bönke, own calculations.Notes: Internal rates of return by cohort group and decile based on 2015 real values. $95 \%$ confidence bands account for sample variation. Panel (a): homogeneous mortality rates. Panel (b): heterogeneous mortality rates. 
pattern. This is consistent with the results in Panel (a), showing a particular high IRR for the bottom decile. The finding is related to generous early retirement schemes, especially for disabled persons. Still, for cohorts 1935-37, the IRR at the bottom (1.2\%) is significantly lower than at the top (1.5\%). For younger cohorts, the results are even stronger. Here we find an increasing pattern of the IRR. For instance, cohorts 1947-1949 reveal an IRR of $1.16 \%$ at the top, which is about three times the IRR at the bottom $(0.38 \%)$.

Figure 6: Difference between IRR with and without differential mortality by decile over cohorts

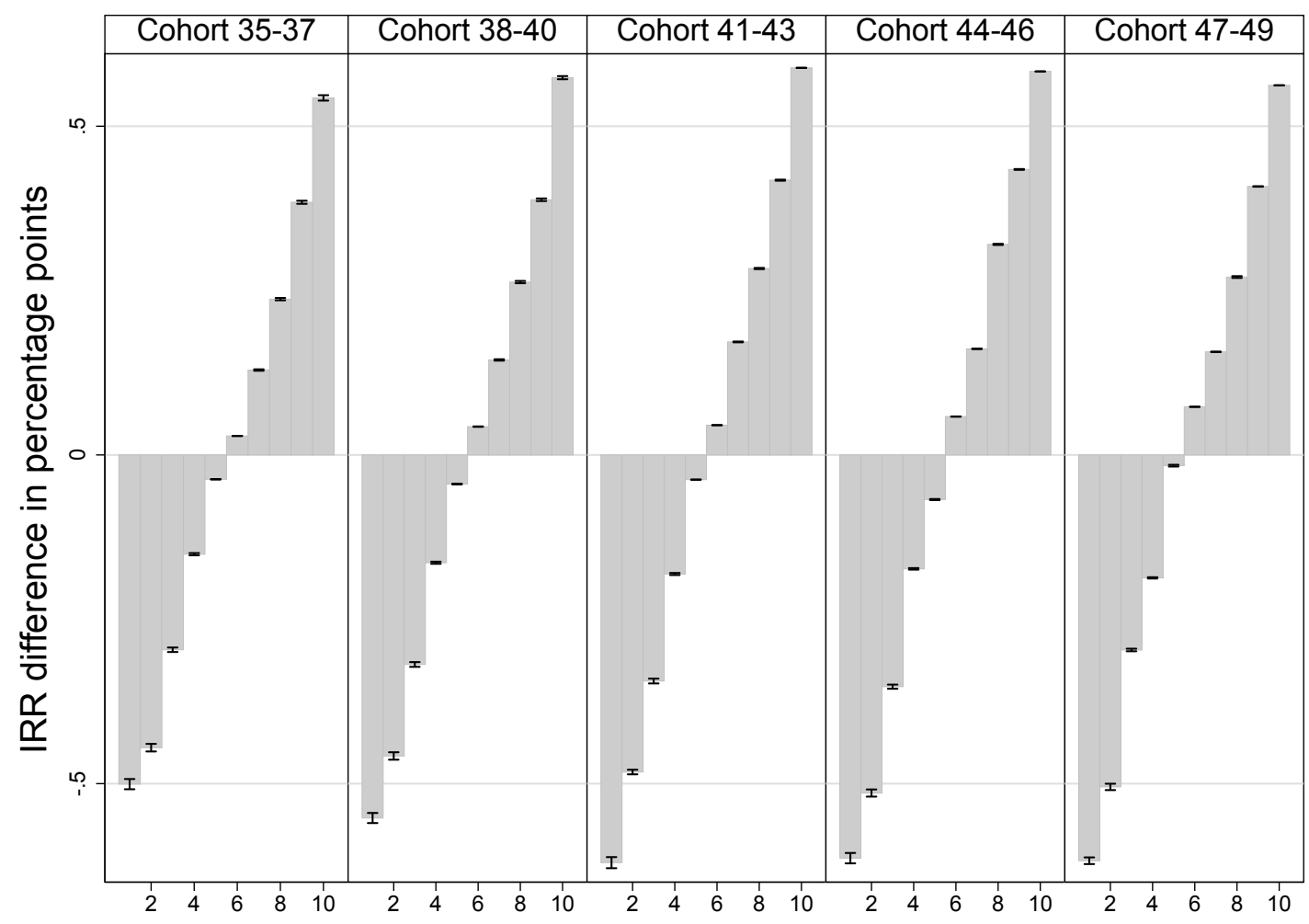

Source: FDZ-RVVSKT2002, 2004-15_Bönke, own calculations. Notes: Difference between internal rates of return under the assumption of heterogeneous and homogeneous mortality by cohort group and decile based on 2015 real values. 95\% confidence bands account for sample variation.

The differences in the distributions of the IRR between the scenarios with and without heterogeneous mortality (Figure 6) isolate the distributional effects of earnings related differences in life expectancy. For deciles below the median, we find that the IRR is sig- 
nificantly lower under the assumption of heterogeneous mortality; in contrast, for deciles above the median, the IRR increase. The differences are sizable: for cohorts 1935-37 the IRR are by 0.5 percentage points lower at the bottom and about 0.5 percentage points higher at the top. In relative terms, both effects correspond to an about $30 \%$ change of the IRR. In line with the increasing longevity gap, the differential effect increases across cohorts.

Our findings are consistent with the mentioned results for US Social Security, which suggest that heterogeneity in life expectancy reduces the progressivity of the system. The distributional implications for the German pension system are even stronger: the regressive effects of earnings-related life expectancy outweigh the progressive effects of early retirement and disability arrangements. Therefore the pension system is clearly regressive. Moreover, our results show important changes between cohorts. In addition to the overall decline in the system's rentability for younger cohorts, the increasing longevity gap increases the system's regressivity.

The final sections provide evidence that our results are robust to two important extensions. First, we show that the regressive effects of the pension system persist when accounting for survivor pensions in addition to individual pensions. Second, we use external data to approximate mortality rates before age 65 , which allows us to look at the distributional effects of heterogeneity in mortality rates over a longer age range.

\subsection{Extension 1: Survivor pensions as additional benefits}

Heterogeneous life expectancy not only matters with respect to own pensions, but also affects the distributional implications of survivor pensions. We can use the estimated heterogeneity in the mortality of widows, in order to explicitly account for differences in the expected duration of benefit recipience. Over the considered period, German pension insurance spends about $20 \%$ of its retirement expenses on widow(er) pensions (Deutsche Rentenversicherung (2015)). Widow(er) pensions are also proportional to individual contributions and support the spouse's living standard in case of low own old-age income. Therefore, these pensions can be regarded as additional returns to pension contributions.

Widow(er) pensions may have distributional effects for three reasons. First, in case of an early death, survivors potentially benefit from survivor pensions for a longer time because the survivor starts receiving the pension at a younger age. This could counteract the regressive effects of heterogeneous mortality rates. Second, as documented above, spouses of high earners have a higher life expectancy (Figure 3). Hence, survivor pensions could further enhance the regressive influence of heterogeneous mortality on the pension 
Figure 7: Pension wealth and returns of West German men including survivor pensions

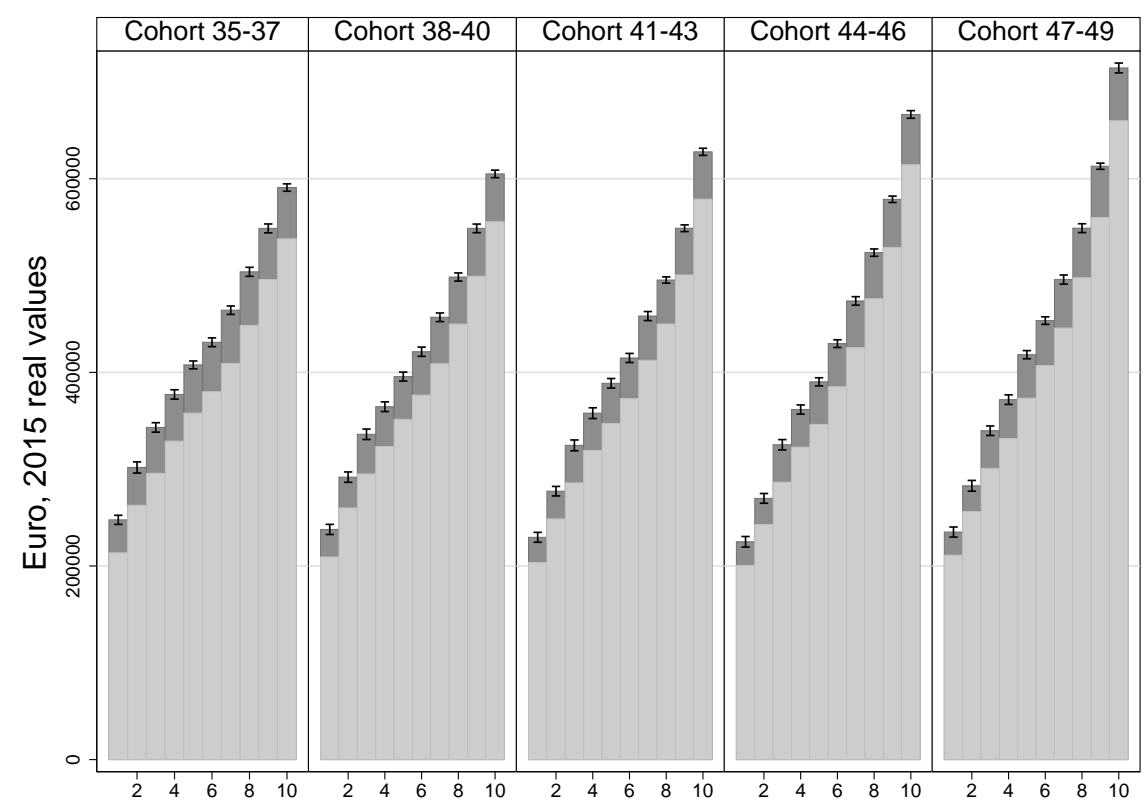

(a)

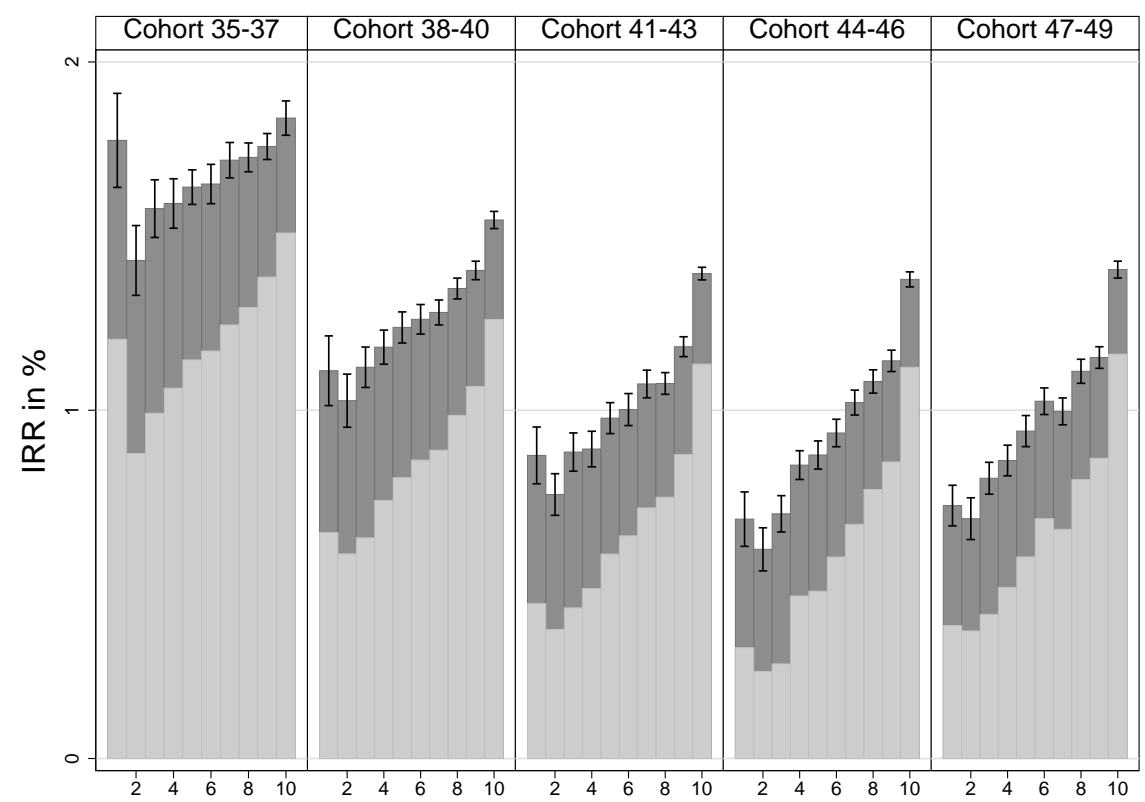

(b)

Source: FDZ-RVVSKT2002, 2004-15_Bönke, own calculations. Notes: Pension wealth and IRR by cohort group and decile based on 2015 real values. Dark grey areas indicate the additional pension wealth or internal rate of return when accounting for survivor benefits in addition to individual benefits (light grey). 95\% confidence bands account for sample variation. 
system. Third, the share of surviving spouses may differ by lifetime earnings and e.g. a regressive effect could emerge if the lifetime poor are less likely be married and, thus, to leave a surviving spouse at a given age of death. To incorporate widow pensions in our estimation, we need to combine the probability of receiving a survivor benefit with the pension level. Both are obtained from SK90 data (see Appendix IV for details).

Figure 7 shows the distributional effects of the pension system when we consider survivor pensions (dark grey) in addition to own entitlements (light grey). Panel (a) presents the distribution of accumulated pension wealth; Panel (b) displays the resulting IRR. We find that survivor pensions increase pension wealth for all deciles, and while the upper deciles gain more in absolute terms, lower deciles benefit over-proportionally. This is reflected by the larger increases of the IRR both in relative and absolute terms. For example, for cohorts $1947-49$ the IRR increases from $0.38 \%$ to $0.73 \%$ at the bottom and from $1.16 \%$ to $1.4 \%$ at the top. Hence, the distributional effect of the earlier death of low earners dominates the regressive effects of longer living widows and higher marriage rates of high earners. However, distributional effects of the pension system remain regressive - in particular over the largest part of the distribution IRR are increasing with lifetime earnings.

\subsection{Extension 2: Differential mortality before age 65}

Empirical evidence shows that heterogeneous mortality by education, earnings, and wealth exists before age 65, see e.g. Cutler et al. (2006). This might also have distributional implications for the pension system. In particular, if individuals die before entering retirement, they do not receive pensions, despite their contributions made to the pension insurance ${ }^{25}$ This implies that the regressive effects of the pension system might be stronger than previously documented. Since the data does not allow to estimate cohort-specific mortality rates by lifetime earnings before age 65 , we approximate the mortality rates by combining age- and cohort-specific mortality rates provided by the German Federal Statistical Offic $e^{26}$ and our estimated heterogeneous mortality rates at age 65 .

In more detail, we assign our estimated heterogeneity at age 65 to all ages from 14 to 64 and rescale the rates to match the average age- and cohort-specific rates provided by Federal Statistical Office ${ }^{27}$. This approximation rests on the assumption that age-

\footnotetext{
${ }^{25}$ Of course, they can still leave survivor pensions.

${ }^{26}$ Available online at https://www.destatis.de/DE/Publikationen/Thematisch/Bevoelkerung/Bevoelkerungsbewegung/Kohortensterbetafeln.html (accessed on February 1, 2017). The rates are computed based on German register data.

${ }^{27}$ We do not consider mortality rates before age 14 . Before age 14 , individuals do not contribute to the
} 
Figure 8: Pension wealth and rates of return accounting for mortality before age 65

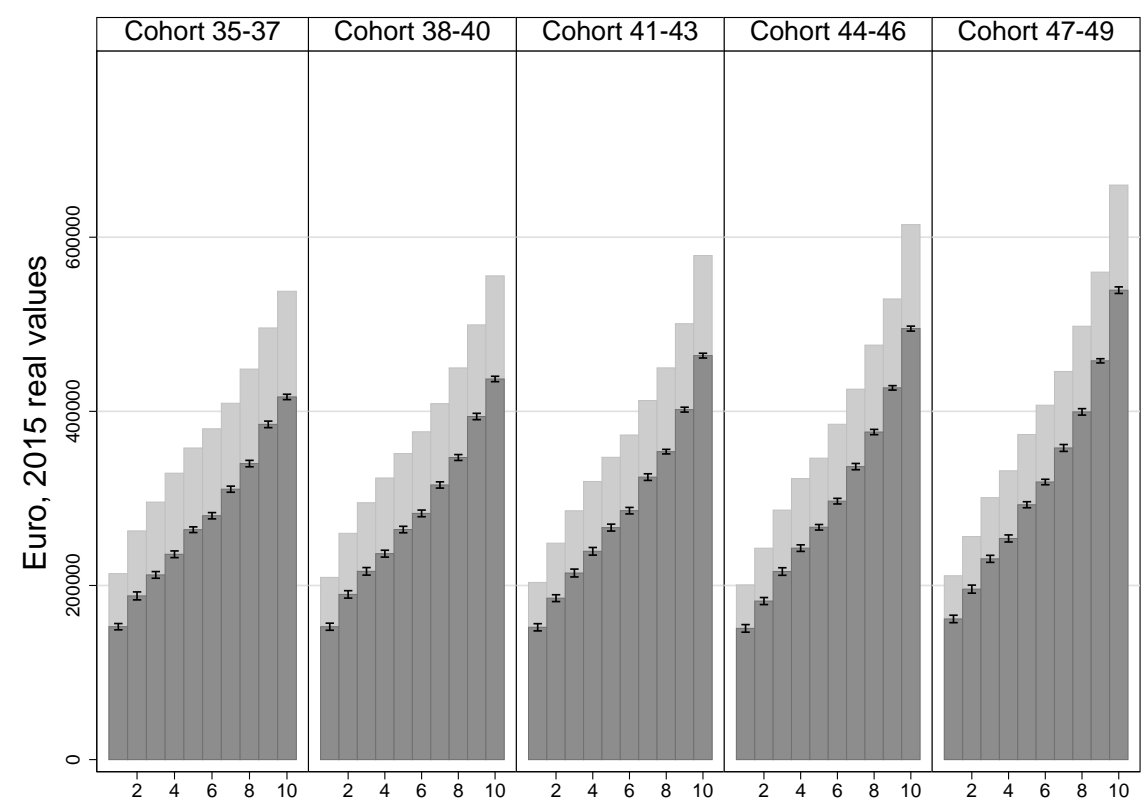

(a)

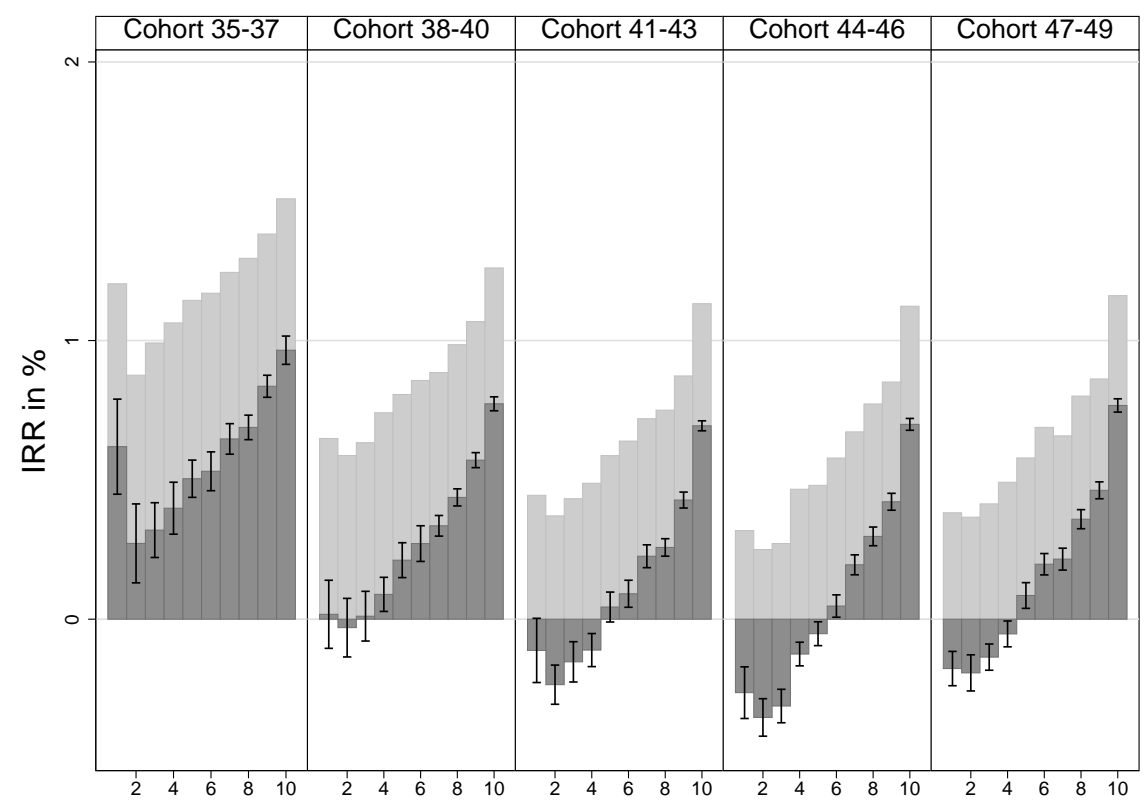

(b)

Source: FDZ-RVVSKT2002, 2004-15_Bönke, own calculations. Notes: Pension wealth and IRR by cohort group and decile based on 2015 real values. Dark grey areas indicate the pension wealth or internal rate of return when accounting for mortality before age 65 in contrast to benefits conditional on reaching age 65 (light grey). 95\% confidence bands account for sample variation. 
specific heterogeneity is constant in relative terms before age 65 . Thus, we do not capture potential changes in the distribution of age-specific mortality rates between cohorts, as discussed in Currie and Schwandt (2016). As documented in Figure A.3 in Appendix I. heterogeneity in mortality risks across deciles of lifetime earnings declines in age. If this relationship between age and mortality differences also holds before age 65 , this would suggest even larger heterogeneity before age 65 . Therefore, our assumption of constant differences in mortality rates is rather conservative and in this sense our results could be interpreted as lower bound effects.

Figure A.5 in Appendix V displays predicted mortality and survival rates until age 65 by deciles of lifetime earnings, where the survival rates are conditional on reaching age 14. The deciles refer to the lifetime earnings that the individuals would achieve if reaching age 65. For cohorts 1947-49, the survival difference at age 65 between top and bottom decile amounts to 14.4 percentage points ( $75.8 \%$ versus $90.2 \%)$. For cohorts 1935-37, this difference is 17.5 percentage points. The larger difference for older cohorts follows from their higher level of average mortality before age 65 . Further, our results suggest low effects of heterogeneous mortality before age 40 and increasing effects toward age 65 .

Figure 8 compares the distribution of pension wealth and IRR with heterogeneous mortality rates before age 65 (dark grey) to our main results (light grey), see as well Figures Appendix III and 5. As expected, the regressive effects of the pension system are even stronger with heterogeneous mortality before age 65. The results show lower pension wealth for all deciles. In relative terms the effects are strongest for the lower deciles (Panel a). This explains why IRR for individuals in the lowest deciles are reduced over-proportionally (Panel b). For individuals in later cohorts IRR become even negative. This is driven by a high share of contributors not reaching retirement age in lower deciles in combination with the reduced rentability of the pension system.

\section{Conclusion}

This study uses German social security records to provide novel evidence about the heterogeneity in life expectancy by lifetime earnings across cohorts 1926-1949. Our results reveal distinct heterogeneity: For West German men of cohorts 1926-28, top and bottom decile experience a difference in life expectancy of about 4 years (30\%) at age 65. This gap widens to about 7 years (almost 50\%) for cohorts 1947-49. This change is driven by a strong increase in life expectancy for the upper deciles. By contrast, life

pension system. 
expectancy increases only slightly for low earners. In addition we document a sizable indirect relation between lifetime earnings and life expectancy: we extend the analysis to the household context, and show differences in life expectancies of widows depending on their husband's lifetime earnings. For widows, the longevity gap between top and bottom quintile increases from about 2.5 years (more than 10\%) to 4 years (about 20\%) during the observed time period.

Further, we provide evidence that the documented heterogeneity has strong distributional implications for the pension system. In line with previous studies, we show that the German pension system is progressive when assuming homogeneous life expectancy within a cohort. However, when accounting for the estimated heterogeneity, the pension system turns regressive. Since high earners receive their pensions for a longer period than low earners, the IRR of the pension system increases with lifetime earnings. Consistent with the rising longevity gap, the regressive effects increase across cohorts. Our results are robust to two important extensions. First, the pension system remains regressive when we consider survivor benefits in addition to own pension benefits. This is the case even though the distributional effect of the earlier death of low earners dominates the regressive effects of longer living widows and higher marriage rates of high earners. Second, using additional assumptions, we provide evidence that the regressive structure becomes stronger when accounting for heterogeneity in mortality rates prior to age 65 .

Our results have important implications for the pension system. For the evaluation of pension reforms, it is important to have reliable estimates about heterogeneity in life expectancy to provide a realistic view about its distributional implications. In particular, when life expectancy is homogeneous, progressive pension formulas, minimum pension schemes, or specific early retirement programs introduce redistribution from individuals with high pension entitlements to individuals with low pension entitlements. Yet, when life expectancy is heterogeneous and related to lifetime earnings, these reforms can help reduce the regressive effects of the pension system.

Moreover our results have more general implications for the discussion on inequality. Several studies have documented an increasing inequality of lifetime earnings during the working life. For example, Kopczuk et al. (2010) and Guvenen et al. (2017) for the US and, similarly, (Bönke et al., 2015) for Germany find growing inequality of male lifetime earnings between cohorts. Our findings reinforce these results: The increasing longevity gap implies that for the considered cohorts the inequality not only increases during the working life but as well during the retirement period. Hence policy makers are confronted with an even stronger increase in inequality. The increasing lifetime inequality can be reduced by the mentioned pension reforms which address regressive effects of 
the pension system. Another promising avenue is policy measures that affect both the distribution of lifetime earnings and life expectancies. For example, educational reforms may target individuals with low lifetime earnings: education can reduce inequality during the working life. At the same time, as documented e.g. in Lleras-Muney (2005), education increases life expectancy and, thus, might help to reduce the heterogeneity in life expectancy. 


\section{References}

Attanasio, O. P. And Pistaferri, L. (2016), Consumption Inequality, Journal of Economic Perspectives, volume 30(2): pages 1-27.

Auerbach, A. J., Charles, K. K., Coile, C. C., Gale, W., Goldman, D., Lee, R., Lucas, C. M., Orszag, P. R., Sheiner, L. M., Tysinger, B., Weil, D. N., Wolfers, J., And Wong, R. (2017), How the Growing Gap in Life Expectancy May Affect Retirement Benefits and Reforms, National Bureau of Economic Research, volume 23329 .

BAGCHI, S. (2016), Differential Mortality and the Progressivity of Social Security, $U p$ john Institute working paper, volume 16(263).

Bönke, T., Corneo, G., And Lüthen, H. (2015), Lifetime Earnings Inequality in Germany, Journal of Labor Economics, volume 33(1): pages $171-208$.

Börsch-Supan, A. And Schnabel, R. (1998), Social Security and Declining LaborForce Participation in Germany, American Economic Review: Papers and Proceedings, volume 88(2): pages $173-178$.

Breyer, F. And Hupfeld, S. (2009), Fairness of Public Pensions and Old-Age Poverty, FinanzArchiv, volume 65: pages 358-380.

Chetty, R., Stepner, M., Abraham, S., Lin, S., Scuderi, B., Turner, N., Bergeron, A., And Cutler, D. (2016), The Association Between Income and Life Expectancy in the United States, 2001-2014, The Journal of the Americal Medical Association 315(16): 1750-1766.

Coronado, D. F., Julia and Glass, T. (2002), Long-Run Effects of Social Security Reform Proposals on Lifetime Progressivity, in The Distributional Aspects of Social Security and Social Security Reform, edited by Feldstein, M. And Liebman, J. B., Chicago: University of Chicago Press.

Currie, J. And Schwandt, H. (2016), Mortality Inequality: The Good News from a County-Level Approach, Journal of Economic Perspectives, volume 30(2): pages $29-52$.

Cutler, D., Deaton, A., And Lleras-Muney, A. (2006), The Determinants of Mortality, Journal of Economic Perspectives, volume 20: pages 97-120. 
Deutsche Rentenversicherung (2015), Rentenversicherung in Zeitreihen, volume 22 of DRV-Schriften.

FAn, J. AND GiJBels, I. (1996), Local polynomial modelling and its applications, Chapman and Hall, London.

Fehr, H., Kallweit, M., And Kindermann., F. (2013), Should pensions be progressive?, European Economic Review, volume 63: pages 94-116.

Gustman, A. L. And Steinmeier, T. L. (2001), How effective is redistribution under the social security benefit formula?, Joural of Public Economics, volume 82: pages $1-28$.

Guvenen, F., Kaplan, G., Song, J., And Weidner, J. (2017), Lifetime Incomes in the United States over Six Decades, Working Paper 23371, National Bureau of Economic Research.

Kiebele, E., Jasilionis, D., And Shkolnikov, V. M. (2013), Widening socioeconomic differences in mortality among men aged 65 years and older in Germany, Journal of Epidemiol Community Health, volume 67: page 453457.

Kitagawa, E. M. and Hauser, P. M. (1973), Differential Mortality in the United States: A Study in Socioeconomic Epidemiology., Harvard University Press. Cambridge, MA:.

Kopczuk, W., Saez, E., And Song, J. (2010), Earnings Inequality and Mobility in the United States: Evidence from Social Security Data since 1937, Quarterly Journal of Economics, volume 125(1): pages 91-128.

Liebman, J. B. (2002), Redistribution in the Current U.S. Social Security System, in The Distributional Aspects of Social Security and Social Security Reform, edited by Feldstein, M. And Liebman, J., pages 11-48, University of Chicago Press.

Lleras-Muney, A. (2005), The Relationship Between Education and Adult Mortality in the United States, Review of Economic Studies, volume 72: pages 189-221.

Lüthen, H. (2016), Rates of Return and Early Retirement Disincentives: Evidence from a German Pension Reform, German Economic Review, volume 17(2): pages 206-233, ISSN 1468-0475.

Nadaraya, E. A. (1964), On estimating regression, Theory of Probability \& Its Applications, volume $9(1)$ : pages $141-142$. 
Oeppen, J. and Vaupel, J. W. (2002), Broken Limits to Life Expectancy, Science, volume 296(5570): pages 1029-1031.

Pestieau, P. and Ponthiere, G. (2016), Longevity variations and the Welfare State., Journal of Demographic Economics, volume 82: page 207239.

Saez, E. And Zucman, G. (2016), Wealth Inequality in the United States since 1913: Evidence from Capitalized Income Tax Data, Quarterly Journal of Economics, volume 131(2): pages 519-578.

Sanchez-Romero, M. and Fürnkranz-Prskawetz, A. (2017), Redistributive effects of the US pension system among individuals with different life expectancy, ECON WPS - Vienna University of Technology Working Papers in Economic Theory and Policy 03/2017, Vienna University of Technology, Institute for Mathematical Methods in Economics, Research Group Economics (ECON).

SchröDER, C. (2011), Profitability of pension contributions evidence from real-life employment biographies, Journal of Pension Economics and Finance, (11): pages $311-336$.

von Gaudecker, H. M. And Scholz, R. (2007), Differential mortality by lifetime earnings in Germany, Demographic Research, volume 17(4): pages 83-108.

Waldron, H. (2007), Trends in Mortality Differentials and Life Expectancy for Male Social Security-Covered Workers, By Socioeconomic Status, Social Security Bulletin, volume 67(3): pages 1-28.

Watson, G. S. (1964), Smooth regression analysis, Sankhyāa: The Indian Journal of Statistics, Series A, pages 359-372. 


\section{Appendix I. Descriptive statistics}

Table A.1: Observations of West German male retirees by cohorts

\begin{tabular}{|c|c|c|c|c|c|c|c|}
\hline Cohort & Surviving & Decedent & Total & Cohort & Surviving & Decedent & Total \\
\hline 1905 & 101,692 & 26,2514 & 127,943 & 1930 & $2,678,941$ & 127,314 & $2,806,255$ \\
\hline 1906 & 132,887 & 31,2924 & 164,179 & 1931 & $2,483,456$ & 110,264 & $2,593,720$ \\
\hline 1907 & 175,877 & 39,2439 & 215,120 & 1932 & $2,343,275$ & 96,640 & $2,439,915$ \\
\hline 1908 & 223,875 & 45,9751 & 269,850 & 1933 & $2,242,822$ & 87,019 & $2,329,841$ \\
\hline 1909 & 282,433 & 54,0376 & 336,470 & 1934 & $2,674,049$ & 97,181 & $2,771,230$ \\
\hline 1910 & 338,632 & 60,3394 & 398,971 & 1935 & $2,738,728$ & 92,465 & $2,831,193$ \\
\hline 1911 & 399,581 & 67,0023 & 466,583 & 1936 & $2,659,882$ & 83,115 & $2,742,997$ \\
\hline 1912 & 497,588 & 77,1435 & 574,731 & 1937 & $2,555,821$ & 74,750 & $2,630,571$ \\
\hline 1913 & 580,880 & 83,4644 & 664,344 & 1938 & $2,518,605$ & 69,237 & $2,587,842$ \\
\hline 1914 & 635,146 & 86,0982 & 721,244 & 1939 & $2,472,220$ & 64,435 & $2,536,655$ \\
\hline 1915 & 580,828 & 73,9816 & 654,809 & 1940 & $2,247,875$ & 56,039 & $2,303,914$ \\
\hline 1916 & 509,461 & 59,8989 & 569,359 & 1941 & $1,873,480$ & 44,176 & $1,917,656$ \\
\hline 1917 & 525,305 & 58,0219 & 583,326 & 1942 & $1,307,605$ & 29,391 & $1,336,996$ \\
\hline 1918 & 599,923 & 62,0588 & 661,981 & 1943 & $1,152,980$ & 25,032 & $1,178,012$ \\
\hline 1919 & $1,009,891$ & 97,2582 & $1,107,149$ & 1944 & $1,115,988$ & 22,488 & $1,138,476$ \\
\hline 1920 & $1,428,648$ & 128,4031 & $1,557,051$ & 1945 & 673,340 & 12,939 & 686,279 \\
\hline 1921 & $1,605,309$ & 135,5594 & $1,740,868$ & 1946 & 643,361 & 11,892 & 655,253 \\
\hline 1922 & $1,692,026$ & 132,4239 & $1,824,449$ & 1947 & 523,445 & 8,976 & 532,421 \\
\hline 1923 & $1,721,222$ & 124,6211 & $1,845,843$ & 1948 & 366,094 & 5,957 & 372,051 \\
\hline 1924 & $1,839,665$ & 123,2597 & $1,962,924$ & 1949 & 187,811 & 2,872 & 190,683 \\
\hline 1925 & $2,254,473$ & 139,2890 & $2,393,762$ & & & & \\
\hline 1926 & $2,453,524$ & 140,0769 & $2,593,600$ & & & & \\
\hline 1927 & $2,565,114$ & 141,5257 & $2,706,639$ & & & & \\
\hline 1928 & $2,773,591$ & 148,5769 & $2,922,167$ & & & & \\
\hline 1929 & $2,695,413$ & 137,3438 & $2,832,756$ & & & & \\
\hline Total & & & & & $63,082,762$ & $3,395,316$ & $66,478,078$ \\
\hline
\end{tabular}

Source: SK90, waves 1992-2015. Notes: The data covers the universe of all pensioners. It contains information about individual pension entitlements, pension level, survivor pensions, and date of death. More specifically, we observe if an individual pension was discontinued the past 12 months preceding the reporting date (November 30th). For an old-age pension, the only reason for a discontinuation is the death of the respective individual. The sample is restricted to West German men with at least 30 accumulated earnings points. This corresponds to about $75 \%$ of the original sample. 
Table A.2: Observations of West German widows by cohorts

\begin{tabular}{|c|c|c|c|c|c|c|c|}
\hline Cohort & Surviving & Decedent & $\overline{\text { Total }}$ & Cohort & Surviving & Decedent & $\overline{\text { Total }}$ \\
\hline 1890 & 11,133 & 2,943 & 14,076 & 1920 & $1,087,141$ & 69,872 & $1,157,0139$ \\
\hline 1891 & 14,788 & 3,783 & 18,571 & 1921 & $1,083,871$ & 66,189 & $1,150,0608$ \\
\hline 1892 & 19,224 & 4,484 & 23,708 & 1922 & $1,006,115$ & 58,804 & $1,064,9198$ \\
\hline 1893 & 25,105 & 5,787 & 30,892 & 1923 & 910,865 & 50,193 & 961,0588 \\
\hline 1894 & 33,736 & 7,939 & 41,675 & 1924 & 866,994 & 44,651 & 911,6450 \\
\hline 1895 & 44,602 & 10,004 & 54,606 & 1925 & 932,812 & 45,360 & 978,1725 \\
\hline 1896 & 58,973 & 12,793 & 71,766 & 1926 & 898,093 & 41,347 & 939,4401 \\
\hline 1897 & 76,448 & 15,935 & 92,383 & 1927 & 884,578 & 38,052 & 922,6307 \\
\hline 1898 & 100,160 & 20,356 & 120,516 & 1928 & 901,570 & 36,410 & 937,9802 \\
\hline 1899 & 142,295 & 27,487 & 169,782 & 1929 & 802,147 & 29,463 & 831,6102 \\
\hline 1900 & 182,961 & 32,770 & 215,731 & 1930 & 737,877 & 24,674 & 762,5517 \\
\hline 1901 & 240,438 & 41,211 & 281,649 & 1931 & 623,335 & 19,367 & 642,7022 \\
\hline 1902 & 301,387 & 48,764 & 350,151 & 1932 & 526,712 & 14,817 & 541,5295 \\
\hline 1903 & 355,911 & 54,918 & 410,829 & 1933 & 452,272 & 11,867 & 464,1397 \\
\hline 1904 & 434,529 & 63,688 & 498,217 & 1934 & 485,756 & 11,861 & 497,6177 \\
\hline 1905 & 503,946 & 70,359 & 574,305 & 1935 & 436,977 & 9,706 & 446,683 \\
\hline 1906 & 568,710 & 74,573 & 643,283 & 1936 & 371,218 & 7,796 & 379,014 \\
\hline 1907 & 644,389 & 80,831 & 725,220 & 1937 & 309,628 & 6,128 & 315,756 \\
\hline 1908 & 711,445 & 83,804 & 795,249 & 1938 & 268,814 & 4,995 & 273,809 \\
\hline 1909 & 775,573 & 87,420 & 862,993 & 1939 & 234,541 & 4,128 & 238,669 \\
\hline 1910 & 816,472 & 86,705 & 903,177 & 1940 & 192,304 & 3,326 & 195,630 \\
\hline 1911 & 837,126 & 85,664 & 922,790 & 1941 & 139,682 & 2,308 & 141,990 \\
\hline 1912 & 920,461 & 89,301 & $1,009,762$ & 1942 & 87,457 & 1,385 & 88,842 \\
\hline 1913 & 954,719 & 86,207 & $1,040,926$ & 1943 & 69,869 & 979 & 70,848 \\
\hline 1914 & 941,166 & 81,203 & $1,022,369$ & 1944 & 52,301 & 721 & 53,022 \\
\hline 1915 & 787,313 & 64,514 & 851,827 & 1945 & 27,189 & 376 & 27,565 \\
\hline 1916 & 612,442 & 47,992 & 660,434 & 1946 & 20,807 & 237 & 21,044 \\
\hline 1917 & 570,555 & 42,200 & 612,755 & 1947 & 13,661 & 152 & 13,813 \\
\hline 1918 & 578,016 & 41,477 & 619,493 & 1948 & 7,158 & 78 & 7,236 \\
\hline 1919 & 855,684 & 57,688 & 913,372 & 1949 & 2,627 & 23 & 2,650 \\
\hline Total & & & & & $27,554,078$ & $2,038,065$ & $29,592,143$ \\
\hline
\end{tabular}

Source: SK90, waves 1992-2015. Notes: The data covers the universe of all pensioners. It contains information about individual pension entitlements, pension level, survivor pensions, and date of death. More specifically, we observe if an individual pension was discontinued the past 12 months preceding the reporting date (November 30th). For a survivor pension, the only reason for a discontinuation is the death of the respective individual. The sample is restricted to widows of West German men with at least 30 accumulated earnings points. 
Table A.3: Observations of West German men in biography sample by decile and cohorts

\begin{tabular}{lcccccc}
\hline \hline Decile & \multicolumn{6}{c}{ Cohort group } \\
& $35-37$ & $38-40$ & $41-43$ & $44-46$ & $47-49$ & \\
\hline 1 & 344 & 275 & 316 & 280 & 312 & 1527 \\
2 & 253 & 291 & 324 & 264 & 261 & 1393 \\
3 & 282 & 275 & 308 & 271 & 259 & 1395 \\
4 & 298 & 273 & 291 & 299 & 249 & 1410 \\
5 & 311 & 287 & 278 & 310 & 290 & 1476 \\
6 & 300 & 302 & 289 & 290 & 280 & 1461 \\
7 & 301 & 299 & 286 & 294 & 264 & 1444 \\
8 & 277 & 315 & 320 & 252 & 256 & 1420 \\
9 & 302 & 298 & 302 & 249 & 241 & 1392 \\
10 & 305 & 310 & 292 & 268 & 242 & 1417 \\
\hline Total & 2973 & 2925 & 3006 & 2777 & 2654 & 14335 \\
\hline \hline
\end{tabular}

Source: FDZ-RVVSKT2002, 2004-15_Bönke. Notes: The data is a random sub-sample of all individuals covered by the pension insurance. It includes complete monthly employment biographies from ages 14 to 67 for cohorts 1935 through 1949. The estimation sample is restricted to West German men with at least 30 accumulated earnings points and further excludes those with special pension arrangements, especially miners. The deciles refer to the distribution of lifetime earnings. The data is accessible through controlled remote computing only. A $25 \%$ subsample is available as scientific use file.

Appendix, p. 3 
Table A.4: Months spent in labor market states of West German men from ages 14 to 65

\begin{tabular}{lcccccc}
\hline \hline Decile & Employment & Retirement & Unemployment & Sick leave & Other & Uninsured \\
\hline \multicolumn{2}{l}{ Unrestricted sample } & & & & & \\
1 & 82.5 & 10.4 & 10.3 & 0.9 & 66.8 & 453.1 \\
2 & 182.7 & 25.1 & 24.1 & 2.8 & 115.9 & 273.4 \\
3 & 304.4 & 55.0 & 35.7 & 5.8 & 104.2 & 118.9 \\
4 & 392.6 & 62.5 & 30.4 & 8.0 & 70.7 & 59.8 \\
5 & 437.4 & 58.2 & 22.9 & 7.6 & 56.2 & 41.7 \\
6 & 461.2 & 53.3 & 19.0 & 6.1 & 49.9 & 34.5 \\
7 & 474.8 & 48.6 & 17.1 & 5.0 & 48.4 & 30.1 \\
8 & 475.6 & 45.1 & 15.4 & 3.8 & 53.1 & 31.1 \\
9 & 478.4 & 42.7 & 13.1 & 2.2 & 56.2 & 31.5 \\
10 & 501.8 & 28.7 & 6.2 & 1.1 & 57.9 & 28.4 \\
\hline Estimation $\mathbf{s a m p l e}$ & & & & & \\
1 & 362.5 & 51.1 & 35.2 & 6.3 & 86.5 & 82.3 \\
2 & 416.0 & 52.5 & 28.3 & 7.0 & 66.4 & 53.8 \\
3 & 445.3 & 52.4 & 22.8 & 6.9 & 54.6 & 41.9 \\
4 & 462.5 & 51.2 & 19.3 & 5.6 & 49.8 & 35.6 \\
5 & 473.0 & 48.2 & 18.1 & 5.2 & 47.3 & 32.2 \\
6 & 477.5 & 45.0 & 15.6 & 4.5 & 50.5 & 30.9 \\
7 & 477.9 & 44.1 & 14.8 & 3.5 & 52.8 & 31.0 \\
8 & 476.6 & 42.5 & 14.3 & 2.4 & 56.6 & 31.7 \\
9 & 482.5 & 39.5 & 10.4 & 1.6 & 58.6 & 31.4 \\
10 & 509.4 & 24.6 & 5.0 & 1.0 & 56.5 & 27.5 \\
\hline \hline
\end{tabular}

Source: FDZ-RVVSKT2002, 2004-15_Bönke. Notes: The data is a random sub-sample of all individuals covered by the pension insurance. It includes complete monthly employment biographies from ages 14 to 67 for cohorts 1935 through 1949. The estimation sample is restricted to West German men with at least 30 accumulated earnings points and further excludes those with special pension arrangements, especially miners. The deciles refer to the distribution of lifetime earnings. The data is accessible through controlled remote computing only. A $25 \%$ subsample is available as scientific use file. 
Figure A.1: Cut-off values of deciles of earnings point distribution at age 65 over cohorts

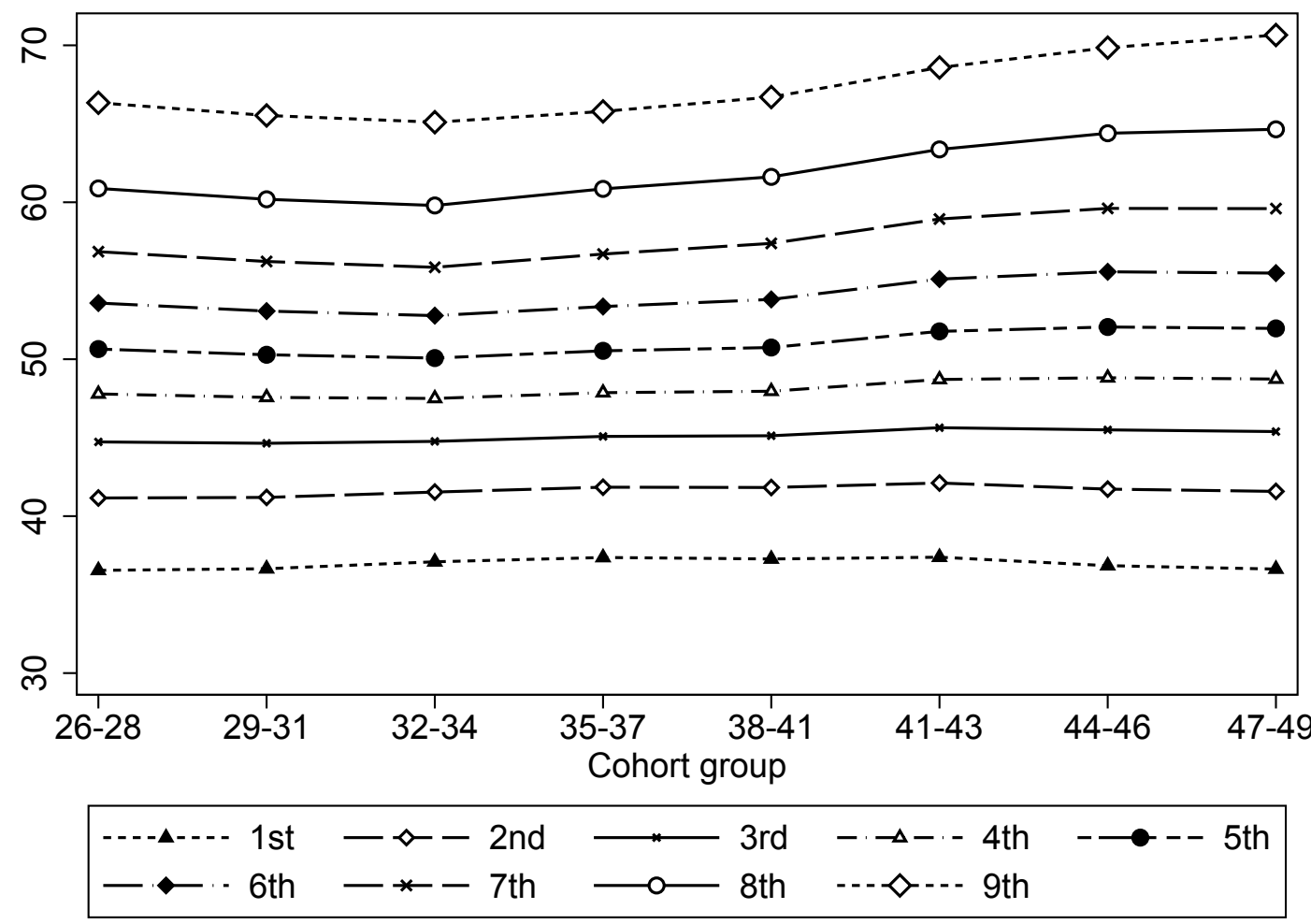

Source: SK90, waves 1992-2015. Notes: The cut-off values at age 65 are computed for individuals born 1926-49 with at least 30 accumulated earnings points. 
Figure A.2: Observed age-specific mortality rates of West German men born between 1926 and 1949 by cohort group and earnings decile

(a) By decile

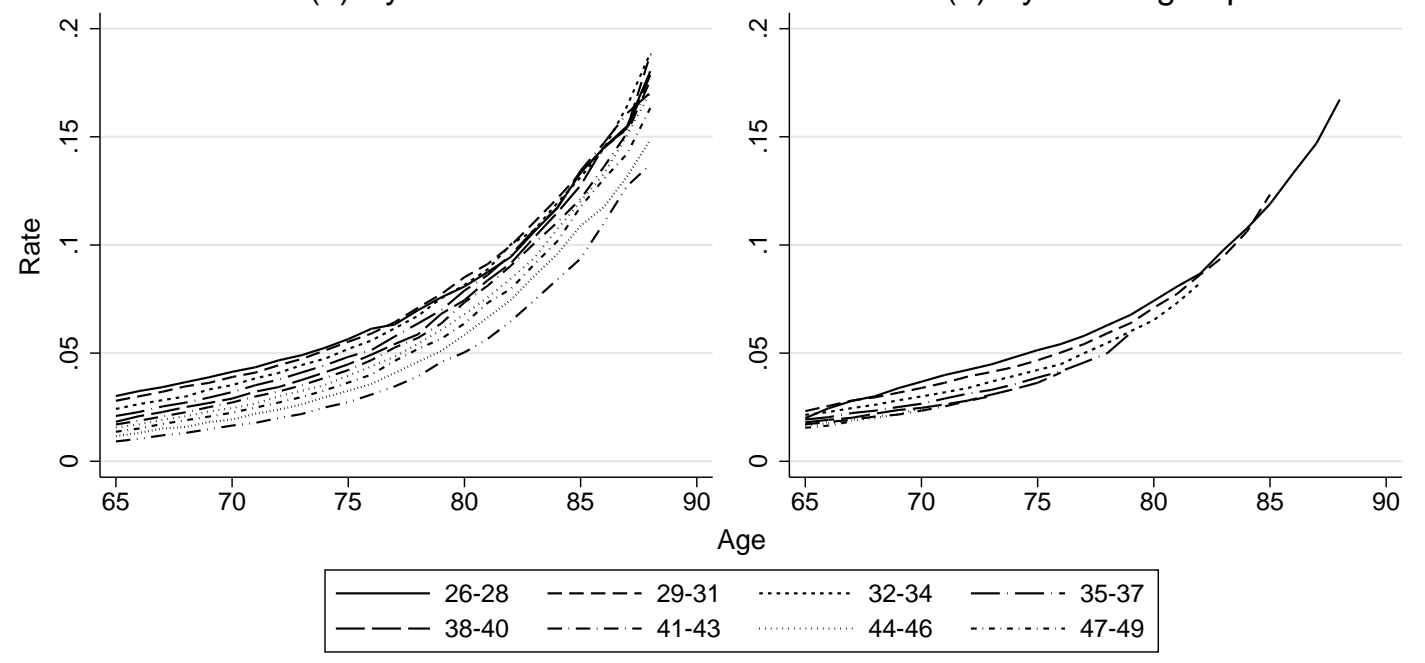

Source: SK90, waves 1992-2015, own calculations.

Figure A.3: Observed age-specific log-odds of mortality of West German men born between 1926 and 1949 by cohort group and earnings decile

(1) By decile

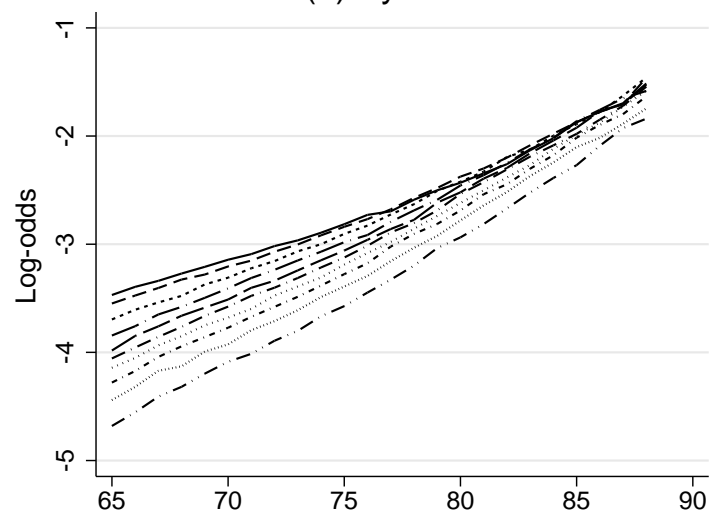

(2) By cohort group

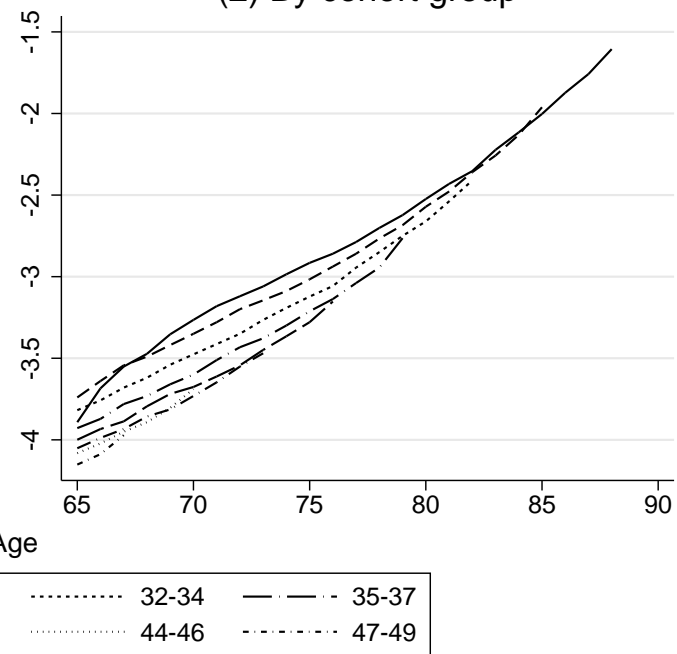

Source: SK90, waves 1992-2015, own calculations. 


\section{Appendix II. Parameter estimates}

Table A.5: Parameter estimates: logistic regression of West German men's mortality I

\begin{tabular}{|c|c|c|}
\hline & Estimate & Standard error \\
\hline Age & 6.070 & 0.7446 \\
\hline Age $^{2} / 100$ & -11.845 & 1.4072 \\
\hline $\mathrm{Age}^{3} / 100^{2}$ & 10.245 & 1.1765 \\
\hline $\mathrm{Age}^{4} / 100^{3}$ & -3.272 & 0.3672 \\
\hline Cohorts $1908-10$ & 0.006 & 0.0133 \\
\hline Cohorts $1911-13$ & -0.001 & 0.0127 \\
\hline Cohorts $1914-16$ & -0.011 & 0.0130 \\
\hline Cohorts 1917 - 19 & -0.047 & 0.0132 \\
\hline Cohorts $1920-22$ & -0.092 & 0.0124 \\
\hline Cohorts $1923-25$ & -0.150 & 0.0125 \\
\hline Cohorts $1926-28$ & -0.182 & 0.0125 \\
\hline Cohorts $1929-31$ & -0.180 & 0.0128 \\
\hline Cohorts $1932-34$ & -0.195 & 0.0131 \\
\hline Cohorts $1935-37$ & -0.252 & 0.0133 \\
\hline Cohorts $1938-40$ & -0.287 & 0.0137 \\
\hline Cohorts $1941-43$ & -0.292 & 0.0148 \\
\hline Cohorts $1944-46$ & -0.312 & 0.0171 \\
\hline Cohorts $1947-49$ & -0.353 & 0.0226 \\
\hline 2nd decile & 16.583 & 21.5386 \\
\hline 3rd decile & 17.058 & 21.9528 \\
\hline 4th decile & -27.067 & 22.2532 \\
\hline 5th decile & -40.145 & 22.5638 \\
\hline 6 th decile & -3.791 & 22.4194 \\
\hline 7th decile & -1.024 & 22.5306 \\
\hline 8 th decile & -41.769 & 22.7171 \\
\hline 9th decile & 2.035 & 22.9163 \\
\hline 10th decile & -38.432 & 22.1587 \\
\hline Age $\times 2$ d decile & -0.844 & 1.0907 \\
\hline Age $\times 3$ rd decile & -0.939 & 1.1114 \\
\hline Age $\times 4$ th decile & 1.234 & 1.1261 \\
\hline Age $\times 5$ th decile & 1.906 & 1.1411 \\
\hline Age $\times 6$ th decile & 0.027 & 1.1329 \\
\hline Age $\times 7$ th decile & -0.094 & 1.1377 \\
\hline Age $\times 8$ th decile & 1.952 & 1.1459 \\
\hline Age $\times 9$ th decile & -0.297 & 1.1547 \\
\hline Age $\times 10$ th decile & 1.713 & 1.1130 \\
\hline Age $^{2} / 100 \times 2$ nd decile & 1.577 & 2.0619 \\
\hline Age $^{2} / 100 \times 3 r d$ decile & 1.860 & 2.1006 \\
\hline Age ${ }^{2} / 100 \times 4 t h$ decile & -2.152 & 2.1273 \\
\hline Age $^{2} / 100 \times 5$ th decile & -3.465 & 2.1545 \\
\hline Age $^{2} / 100 \times 6$ th decile & 0.145 & 2.1373 \\
\hline Age $^{2} / 100 \times 7$ th decile & 0.323 & 2.1449 \\
\hline Age $^{2} / 100 \times 8$ th decile & -3.527 & 2.1579 \\
\hline Age $^{2} / 100 \times 9$ th decile & 0.756 & 2.1721 \\
\hline Age $^{2} / 100 \times 10$ th decile & -3.005 & 2.0872 \\
\hline
\end{tabular}

Notes: Mortality probabilities are estimated as a function of an age polynomial interacted with the earnings deciles, cohort-specific effects, fixed effects of the earnings deciles, and the interaction of the cohort and earnings fixed effects. The 1st decile is the baseline of the earnings decile fixed effects and due to the additional interaction terms the effects refer to cohorts 1905-07. As reflected by the confidence bands of the predicted life expectancies, all joint decile effects are highly significant. Further, the joint age effects by decile also differ significantly. The cohorts 1905-1907 are the baseline of the cohort fixed effects, where the cohort fixed effects refer to the 1st decile. Hence, the baseline of the interaction effects is the 1st decile and the cohorts 1905-07. Since the interactions between cohort and earnings fixed effects for cohorts before 1926 are irrelevant for our analysis, they are not shown in the tables; they can be obtained from the authors upon request.

Appendix, p. 7 
Table A.6: Parameter estimates: logistic regression of West German men's mortality II

\begin{tabular}{|c|c|c|}
\hline & Estimate & Standard error \\
\hline$A^{A g e^{3}} / 100^{2} \times 2$ nd decile & -1.286 & 1.7246 \\
\hline Age $^{3} / 100^{2} \times 3 r d$ decile & -1.589 & 1.7567 \\
\hline Age $^{3} / 100^{2} \times 4$ th decile & 1.700 & 1.7782 \\
\hline Age $^{3} / 100^{2} \times 5$ th decile & 2.843 & 1.7999 \\
\hline Age $^{3} / 100^{2} \times 6$ th decile & -0.216 & 1.7841 \\
\hline Age ${ }^{3} / 100^{2} \times 7$ th decile & -0.320 & 1.7892 \\
\hline Age $^{3} / 100^{2} \times 8$ th decile & 2.887 & 1.7980 \\
\hline Age $^{3} / 100^{2} \times 9$ th decile & -0.716 & 1.8078 \\
\hline Age $^{3} / 100^{2} \times 10$ th decile & 2.401 & 1.7319 \\
\hline Age $^{4} / 100^{3} \times 2$ nd decile & 0.388 & 0.5385 \\
\hline Age $^{4} / 100^{3} \times 3$ rd decile & 0.498 & 0.5484 \\
\hline Age $^{4} / 100^{3} \times 4$ th decile & -0.511 & 0.5549 \\
\hline Age $e^{4} / 100^{3} \times 5$ th decile & -0.885 & 0.5614 \\
\hline Age ${ }^{4} / 100^{3} \times 6$ th decile & 0.082 & 0.5560 \\
\hline Age ${ }^{4} / 100^{3} \times 7$ th decile & 0.101 & 0.5572 \\
\hline Age $^{4} / 100^{3} \times 8$ th decile & -0.896 & 0.5593 \\
\hline Age $e^{4} / 100^{3} \times 9$ th decile & 0.236 & 0.5618 \\
\hline Age $^{4} / 100^{3} \times 10$ th decile & -0.726 & 0.5365 \\
\hline Cohorts $1926-28 \times 2$ nd decile & 0.038 & 0.0185 \\
\hline Cohorts $1926-28 \times 3 r d$ decile & 0.026 & 0.0190 \\
\hline Cohorts $1926-28 \times 4$ th decile & 0.015 & 0.0193 \\
\hline Cohorts $1926-28 \times 5$ th decile & -0.008 & 0.0192 \\
\hline Cohorts $1926-28 \times 6$ th decile & -0.019 & 0.0190 \\
\hline Cohorts $1926-28 \times 7$ th decile & -0.038 & 0.0188 \\
\hline Cohorts $1926-28 \times 8$ th decile & -0.015 & 0.0184 \\
\hline Cohorts $1926-28 \times 9$ th decile & 0.013 & 0.0184 \\
\hline Cohorts $1926-28 \times 10$ th decile & 0.077 & 0.0166 \\
\hline Cohorts $1929-31 \times 2$ nd decile & 0.032 & 0.0189 \\
\hline Cohorts $1929-31 \times 3 r d$ decile & 0.001 & 0.0193 \\
\hline Cohorts $1929-31 \times 4$ th decile & -0.040 & 0.0197 \\
\hline Cohorts $1929-31 \times 5$ th decile & -0.069 & 0.0196 \\
\hline Cohorts $1929-31 \times 6$ th decile & -0.086 & 0.0194 \\
\hline Cohorts $1929-31 \times 7$ th decile & -0.104 & 0.0192 \\
\hline Cohorts $1929-31 \times 8$ th decile & -0.071 & 0.0188 \\
\hline Cohorts $1929-31 \times 9$ th decile & -0.044 & 0.0188 \\
\hline Cohorts $1929-31 \times 10$ th decile & 0.024 & 0.0171 \\
\hline Cohorts $1932-34 \times 2$ nd decile & -0.006 & 0.0193 \\
\hline Cohorts $1932-34 \times 3 r d$ decile & -0.084 & 0.0198 \\
\hline Cohorts $1932-34 \times 4$ th decile & -0.151 & 0.0202 \\
\hline Cohorts $1932-34 \times 5$ th decile & -0.187 & 0.0201 \\
\hline Cohorts $1932-34 \times 6$ th decile & -0.193 & 0.0200 \\
\hline Cohorts $1932-34 \times 7$ th decile & -0.214 & 0.0198 \\
\hline Cohorts $1932-34 \times 8$ th decile & -0.196 & 0.0195 \\
\hline Cohorts $1932-34 \times 9$ th decile & -0.176 & 0.0196 \\
\hline Cohorts $1932-34 \times 10$ th decile & -0.097 & 0.0180 \\
\hline
\end{tabular}

Notes: Mortality probabilities are estimated as a function of an age polynomial interacted with the earnings deciles, cohort-specific effects, fixed effects of the earnings deciles, and the interaction of the cohort and earnings fixed effects. The 1st decile is the baseline of the earnings decile fixed effects and due to the additional interaction terms the effects refer to cohorts 1905-07. As reflected by the confidence bands of the predicted life expectancies, all joint decile effects are highly significant. Further, the joint age effects by decile also differ significantly. The cohorts 1905-1907 are the baseline of the cohort fixed effects, where the cohort fixed effects refer to the 1st decile. Hence, the baseline of the interaction effects is the 1st decile and the cohorts 1905-07. Since the interactions between cohort and earnings fixed effects for cohorts before 1926 are irrelevant for our analysis, they are not shown in the tables; they can be obtained from the authors upon request. 
Table A.7: Parameter estimates: logistic regression of West German men's mortality III

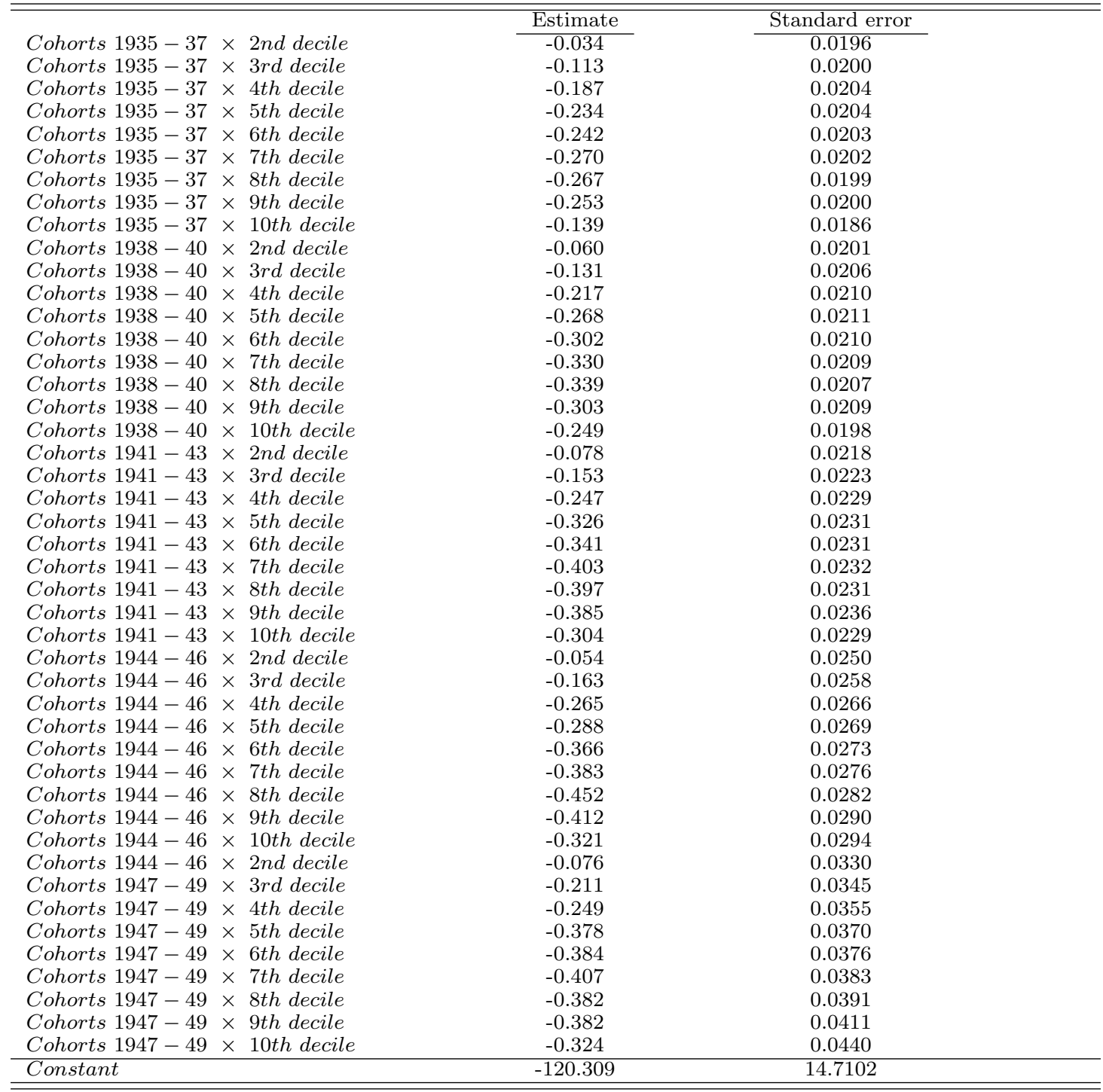

Notes: Mortality probabilities are estimated as a function of an age polynomial interacted with the earnings deciles, cohort-specific effects, fixed effects of the earnings deciles, and the interaction of the cohort and earnings fixed effects. The 1st decile is the baseline of the earnings decile fixed effects and due to the additional interaction terms the effects refer to cohorts 1905-07. As reflected by the confidence bands of the predicted life expectancies, all joint decile effects are highly significant. Further, the joint age effects by decile also differ significantly. The cohorts 1905-1907 are the baseline of the cohort fixed effects, where the cohort fixed effects refer to the 1st decile. Hence, the baseline of the interaction effects is the 1st decile and the cohorts 1905-07. Since the interactions between cohort and earnings fixed effects for cohorts before 1926 are irrelevant for our analysis, they are not shown in the tables; they can be obtained from the authors upon request.

Appendix, p. 9 


\section{Appendix III. Measures for distributional analysis}

\section{Pension wealth}

All pensions are compounded/discounted to the year 2015 with the consumer price index. For the evolution of pensions after 2017 we assume a small real pension growth following Lüthen (2016) (approximately $1.5 \%$ per year).

We consider pension wealth at age 65 . The pension wealth in the baseline scenario consists of the sum of pensions received from retirement age $R$ until age 65 and the pensions received after age 65 . While pension received prior to age 65 are received with probability 1 , pensions received after age 65 are discounted with mortality rates:

$$
P W=\sum_{a=R}^{65} p_{j, a}+\sum_{a=66}^{100} \phi_{c g, a, d}^{65} p_{j, a},
$$

where $p_{j, a}$ depicts the pensions received of individual $j$ at age $a, R$ indicates the age of retirement, and $\phi_{c g, a, d}^{65}$ is the survival probability of cohort group $c g$ and decile $d$ until age $a$ conditional on reaching age 65 .

In addition to the baseline scenario, we consider two extensions. The first extension includes survivor benefits. The formula for pension wealth then becomes:

$$
P W=\sum_{a=R}^{65} p_{j, a}+\sum_{a=66}^{100}(\phi_{c g, d, a}^{65} p_{j, a}+\underbrace{\left(\phi_{c g, a-1, d}^{65}-\phi_{c g, a, d}^{65}\right) \lambda_{c g, q} \sigma_{c g, q, a} \psi_{c g, q, a} p_{j, a}}_{\text {Survivor extension }})
$$

Where:

- $\lambda_{c g, q}$ is percentage of deceased husbands pension by cohort group $c g$ and earnings quintile $q$;

- $\sigma_{c g, q, a}$ is probability to leave a widow by cohort group $c g$, earnings quintile $q$ and age a; and

- $\psi_{c g, q, a}$ is remaining life expectancy of a widow of cohort group $c g$, earnings quintile $q$ and age a.

In short, the term representing survivor benefits increases pension wealth. The term consists of the survivor pension level ( $\S 46$, SGB IV) multiplied with the probability that the pension is received. This probability consists of two components: (1) the probability that the husband died in the previous year, the difference in conditional survival probabilities between the current and last year, $\phi_{c g, a-1, d}^{65}-\phi_{c g, a, d}^{65}$. Component 
(1) is multiplied by (2), the probability $\sigma_{c g, q, a}$ to leave a widow after death. For the expected pensions amount, the individual pension $p$ is multiplied with the remaining life expectancy of the widow, $\psi_{c g, q, a}$, and the percentage of the husband's pension the widow is entitled to ${ }^{28}$ For further details on the calculation of probabilities see Section 4.3 .

For the second extension, we estimate mortality rates before 65 as depicted in Section 4.4. The pension wealth then becomes:

$$
P W=\sum_{a=R}^{100} \phi_{c g, a, d}^{14} p_{j, a}
$$

where $\phi_{c g, a, d}^{14}$ is the survival probability of cohort group $c g$ and decile $d$ until age $a$ conditional on reaching age 65 .

\section{Internal rate of return}

To express the IRR in year 2015 real values, before calculating the IRR, all values have been compounded/discounted to the year 2015 with the consumer price index. For the evolution of pensions after 2017 we assume a small real pension growth (see the previous subsection on pension wealth). The IRR is the interest rate $i$ that equalizes the stream of contributions $c$ one the left-hand side and the expected stream of pensions $p$ at the age of retirement $R$ on the right-hand side:

$$
\sum_{a=14}^{R} c_{j, a}\left(1+i_{j}\right)^{R-a}=\sum_{a=R}^{65} \frac{p_{j, a}}{\left(1+i_{j}\right)^{R-a}}+\sum_{a=66}^{100} \frac{\phi_{c g, a, d}^{65} p_{j, a}}{\left(1+i_{j}\right)^{R-a}}
$$

Where:

- $c_{j, a}$ is contributions of individual $j$ at age $a$;

- $p_{j, a}$ is pensions received of individual $j$ at age $a$;

- $\phi_{c g, a, d}^{65}$ is the survival probability of cohort group $c g$ and decile $d$ until age $a$ conditional on reaching age 65 ;

- $i_{j}$ is individual rate of return (IRR); and

- $R$ is age of retirement.

\footnotetext{
${ }^{28}$ In general, widow(ers) are entitled to up to $60 \%$ of the deceased partners pension. However if a widow earns income above a certain threshold, the entitlement percentage is reduced. This decrease amounts to $40 \%$ for each EURO that the widow's income exceeds the threshold. We observe the percentage of the husband's former pension that is actually received by the widow. The cohort- and quintile-specific percentage of the husband's former pension, $\lambda_{c g, q}$, fluctuates around 53-55\%.
}

Appendix, p. 11 
The left-hand side contains the contributions from age 14 until retirement age $R$. The right-hand side depicts the pensions from $R$ to age 100 and is split into two parts. The first term represents the pensions from $R$ to age 65 . The second term includes the pensions ranging from age 66 to age 100. Here, $\phi_{v, a, d}$ denotes the decile-, cohort group- and age-specific mortality rates estimated in Section 3. Each term in the equation includes the discount factor $i_{j}$ (the IRR), which balances both sides and is computed from the data on an individual basis.

We consider two extensions to this baseline scenario. The first extension includes survivor benefits. The formula for the IRR then becomes:

$$
\begin{array}{r}
\sum_{a=14}^{R} c_{j, a}\left(1+i_{j}\right)^{R-a}=\sum_{a=R}^{65} \frac{p_{j, a}}{\left(1+i_{j}\right)^{R-a}}+ \\
\sum_{a=66}^{100} \frac{\phi_{c g, d, a}^{65} p_{j, a}+\left(\phi_{c g, a-1, d}^{65}-\phi_{c g, a, d}^{65}\right) \lambda_{c g, q} \sigma_{c g, q, a} \psi_{c g, q, a} p_{j, a}}{\left(1+i_{j}\right)^{R-a}}
\end{array}
$$

Where:

- $\lambda_{c g, q}$ is percentage of deceased husbands pension by cohort group $c g$ and earnings quintile $q$;

- $\sigma_{c g, q, a}$ is probability to leave a widow by cohort group $c g$, earnings quintile $q$ and age a; and

- $\psi_{c g, q, a}$ is remaining life expectancy of a widow of cohort group $c g$, earnings quintile $q$ and age a.

The survivor pension is found exclusively in the second term on the right-hand side. Here, the probability of dying in the previous year, $\phi_{c g, a-1, d}^{65}-\phi_{c g, a, d}^{65}$, is multiplied with the expected remaining life expectancy of the widow $\psi_{c g, q, a}$ and the percentage of the partners' pension that is received by the widow $\lambda_{c g, q}$. Usually, survivor pensions amount to $60 \%$ of the deceased partners pension. However, the $60 \%$ of the husbands' pension is reduced if the survivors' own income exceed a certain threshold. This decrease amounts to $40 \%$ per EURO that the income exceeds the threshold. From the widow pensions, we can further determine the percentage of the husbands' former pension that is actually received by the widow. This percentage is rather stable and $\lambda_{c g, q}$ fluctuates around 53$55 \%$ across cohort groups and quintiles of lifetime earnings. For further details on the calculation see Section 4.3 and the previous subsection on pension wealth.

Appendix, p. 12 
The second extension includes mortality before age 65 . For their calculation see Section 4.4. The formula for the IRR becomes:

$$
\sum_{a=14}^{R} \phi_{c g, a, d}^{14} c_{j, a}\left(1+i_{j}\right)^{R-a}=\sum_{a=R}^{100} \frac{\phi_{c g, a, d}^{14} p_{j, a}}{\left(1+i_{j}\right)^{R-a}}
$$

Now, both the contributions on the left-hand side and the pensions on the right-hand side include the survival probability $\phi_{c g, a, d}^{65}$. Since $\phi_{c g, a, d}^{65}$ now extends for the entire age range, the right-hand side contains only one term.

Appendix, p. 13 


\section{Appendix IV. Surviving widows}

While the SK90 data includes exact pension levels, the probability of survivor pension receipt is more complicated to estimate. For this purpose, we combine information about male mortality rates, probabilities of leaving a widow (that are estimated as described in the following paragraph), and widow mortality rates (computed as described in section 3.4. First, the probabilities of leaving a widow in the case of death in a given year are combined with the probabilities of a surviving widow from all previous years after age 65. Second, we combine these probabilities with the male mortality rates in order to obtain the probabilities of surviving widows, i.e. the probabilities of receiving survivor benefits. Our estimations show that recipience has an inverted $u$-shape over age that differs by quintile. For the lower quintiles, recipience peaks at younger ages than for the upper quintiles. For a depiction, see Figure A.4.

We model the individual i's log odds of leaving a widow at a certain age of death as $\log \frac{\operatorname{Pr}\left(\text { leave }_{i t c q} \mid \text { death at age } \mathrm{t}\right)}{1-\operatorname{Pr}\left(\text { leave }_{i t c q} \mid \text { death at age } \mathrm{t}\right)}=\beta_{0}+\sum_{p=1}^{4} \beta_{p} \mathrm{t}^{p}+\sum_{p=1}^{4} \beta_{p q} \mathrm{t}^{p}+\mu_{q}+\eta_{c}+\nu_{c q}$, where $\mathrm{q}$ is the quintile of the deceased husbands' lifetime earnings, c his cohort group, and age $t$ the age that the deceased husband would have reached at the respective reporting date. Cut-offs defining the quintiles are equal to those for men at age 65 . The model is estimated on a sample combining male death' and widows first receiving survivor benefits in their husbands' year of death. The probability of leaving a widow is zero at age 65 by construction. Estimates can be obtained from the authors upon request.

Appendix, p. 14 
Figure A.4: Probability of surviving widow for West German men conditional on reaching age 65 by earnings quintiles for cohorts $1935-37$ and 1947-49

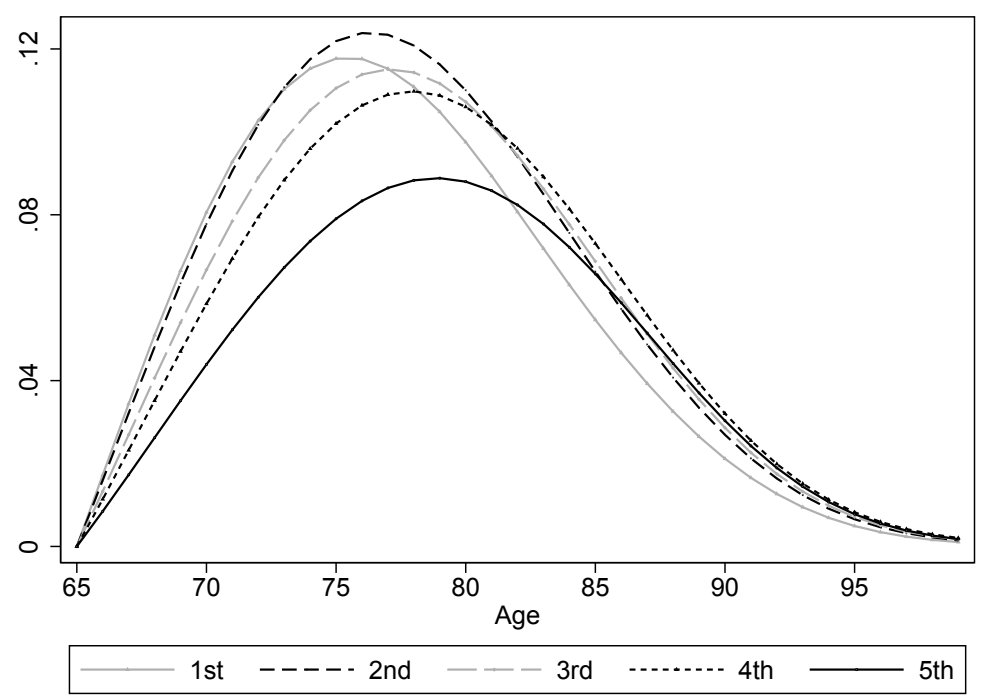

(a)

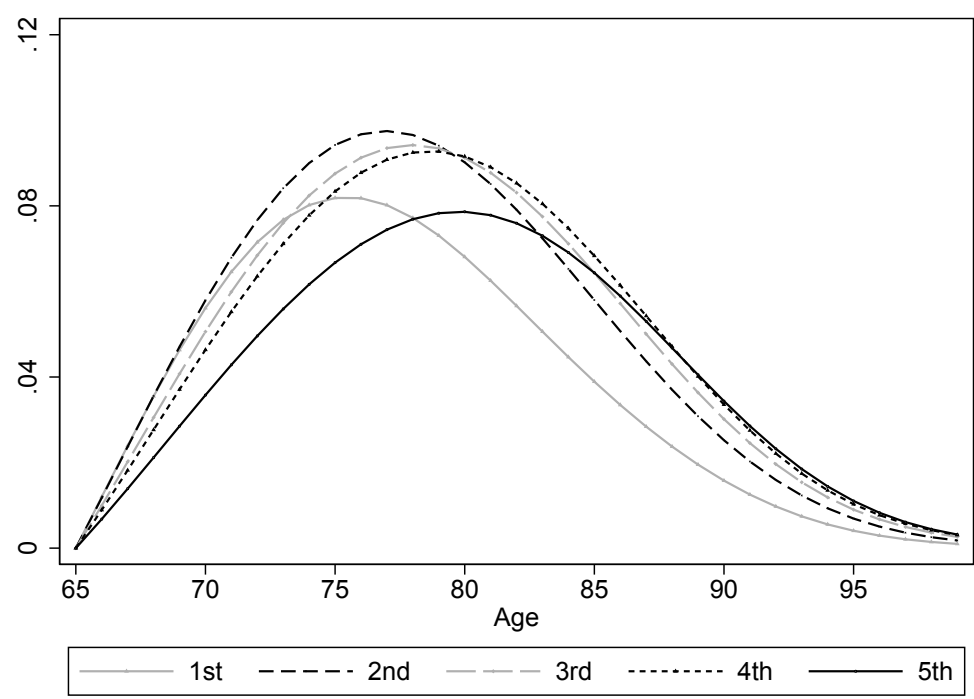

(b)

Notes: Panel (a) displays probabilities for cohorts 1935-37. Panel (b) displays probabilities for cohorts 1947-49. Respective probabilities for the other cohort groups can be obtained upon request.

Appendix, p. 15 


\section{Appendix V. Mortality before age 65}

Figure A.5: Predicted mortality and survival rates for West German men by earnings deciles for ages 14 to 65 for cohorts 1935-37 and 1947-49

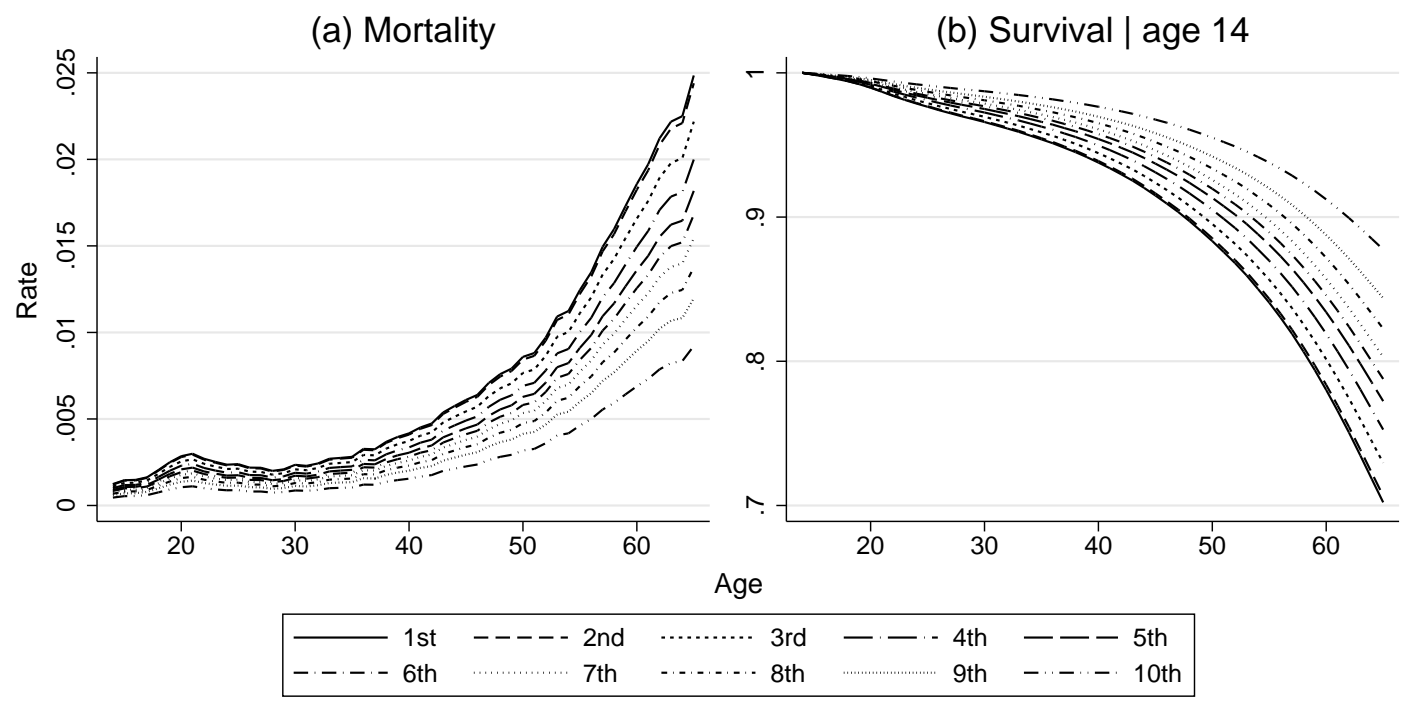

(a)

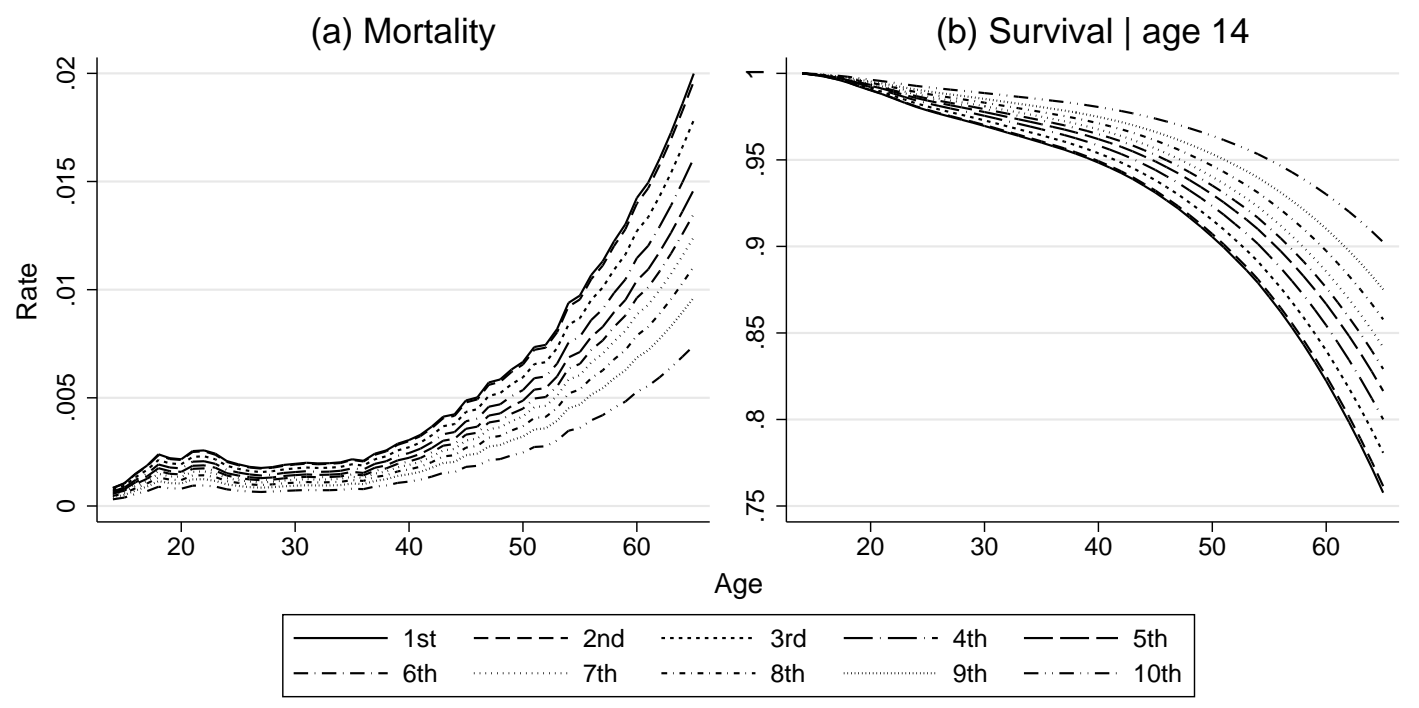

(b)

Notes: Panel (a) displays rates for cohorts 1935-37. Panel (b) displays rates for cohorts 1947-49. Respective rates for the other cohort groups can be obtained upon request.

Appendix, p. 16 


\section{Appendix VI. Robustness checks}

Figure A.6: Comparison of mean predicted mortality rates based on logistic regression model with the respective predictions from a non-parametric estimation

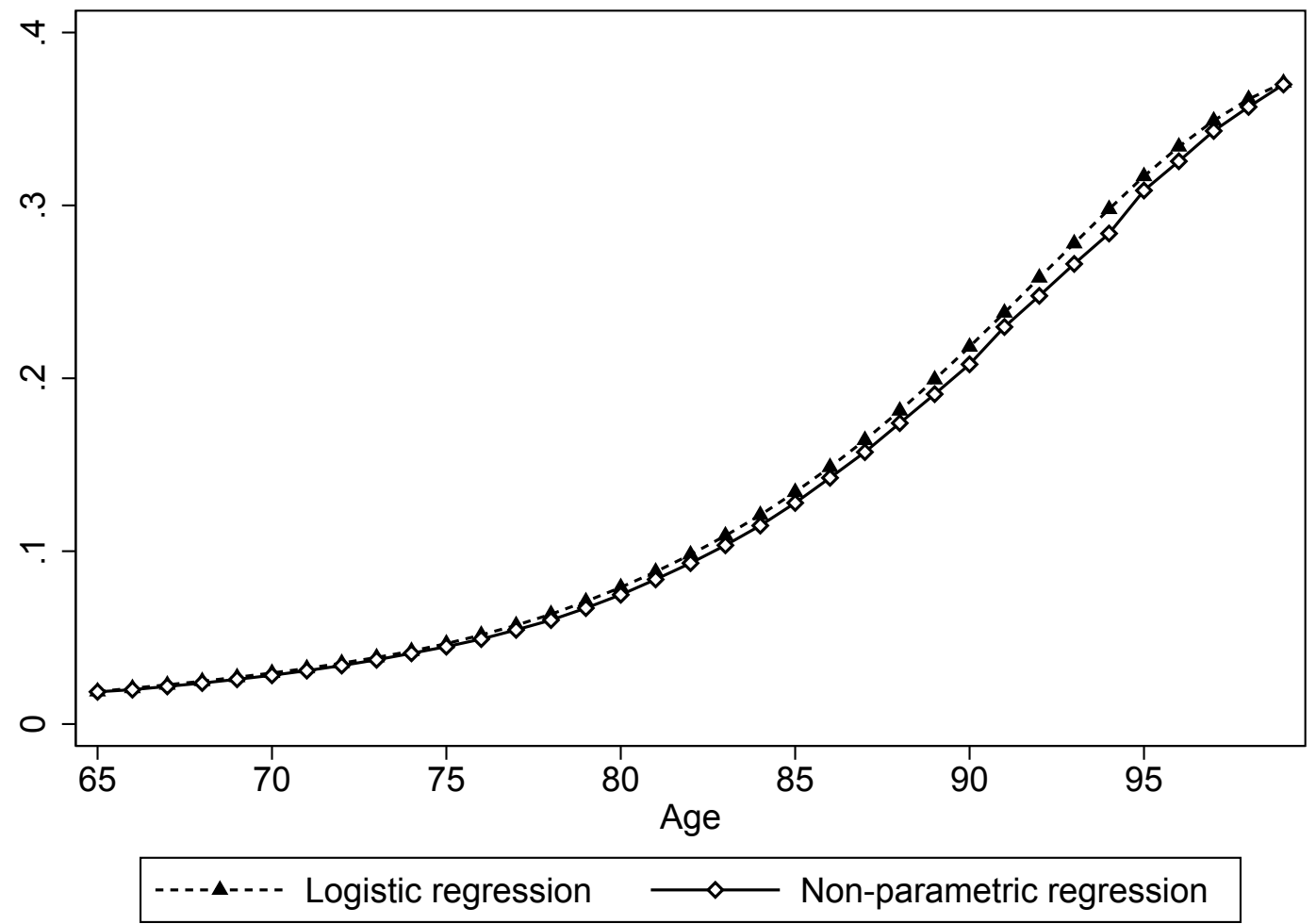

Notes: The graph displays the mean predicted mortality rates in the estimation sample of West German men for cohorts 1905 to 1949. The logistic regression model is specified as described in Section 3.2. The nonparametric estimation relies on a Nadaraya-Watson kernel regression (Nadaraya, 1964, Watson, 1964) with an epanechnikov kernel and the rule-of-thumb bandwidth of Fan and Gijbels (1996). We do not show confidence bands because these bands are extremely narrow for the mean predictions. 
Figure A.7: Life expectancies of West German men at age 65 - alternative samples

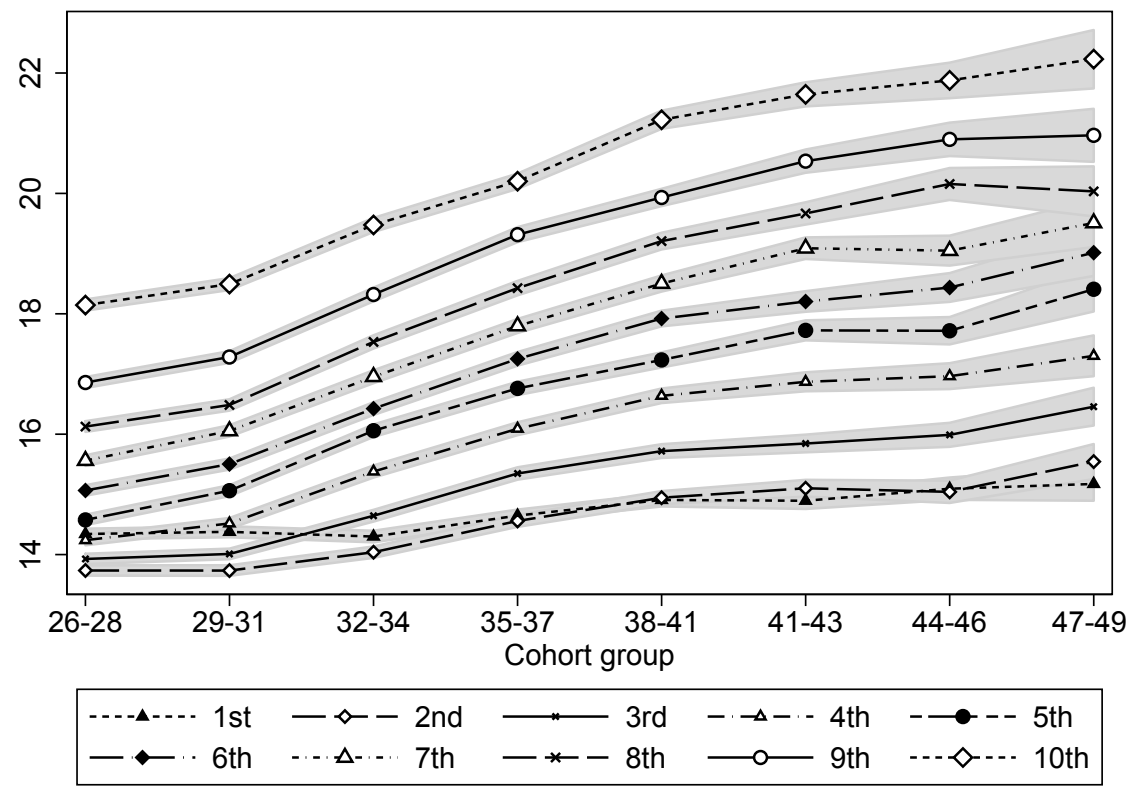

(a)

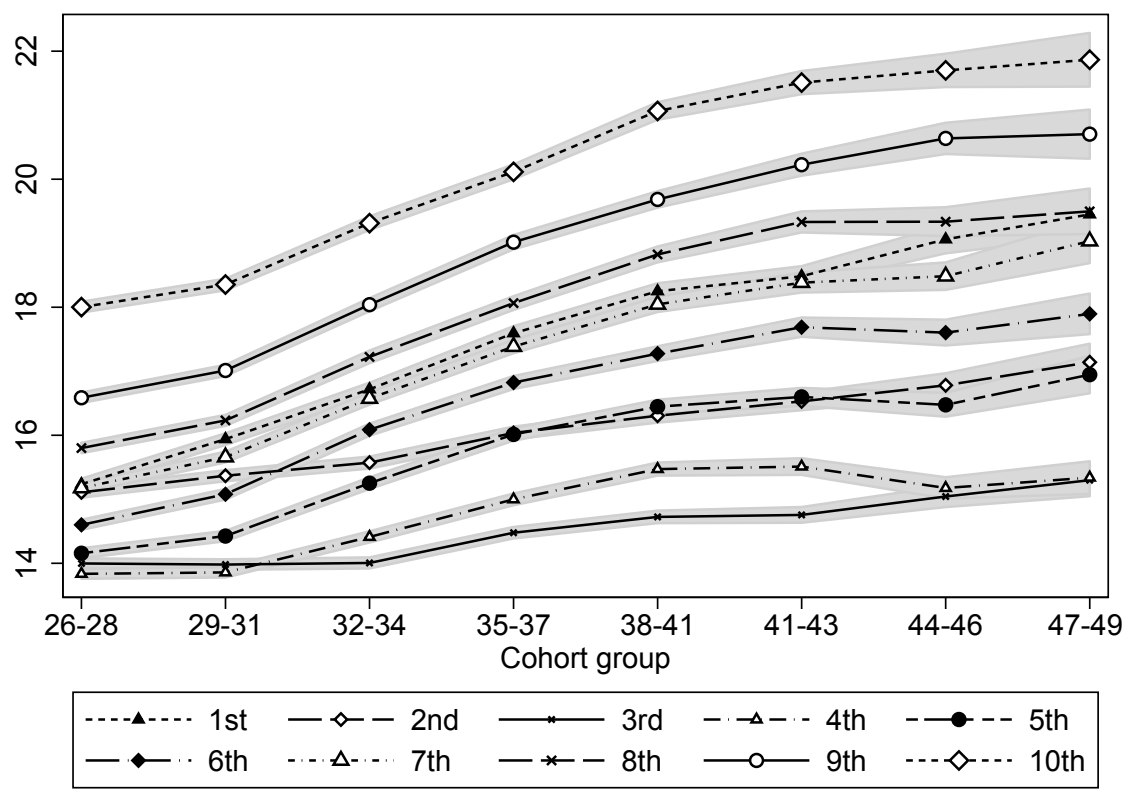

(b)

Notes: Panel (a): estimation based on sample of individuals with more than 25 (instead of 30) earnings points. Panel (b): estimation based on unrestricted sample where lower deciles contain a mix of lifetime poor individuals, civil servants, and the self-employed.

Appendix, p. 18 